Ludovica De Gregorio, Mattia Callegari, Carlo Marin, Marc Zebisch, Lorenzo Bruzzone, Begum Demir, Ulrich Strasser, Thomas Marke, Daniel Günther, Rudi Nadalet, Claudia Notarnicola

\title{
A Novel Data Fusion Technique for Snow Cover Retrieval
}

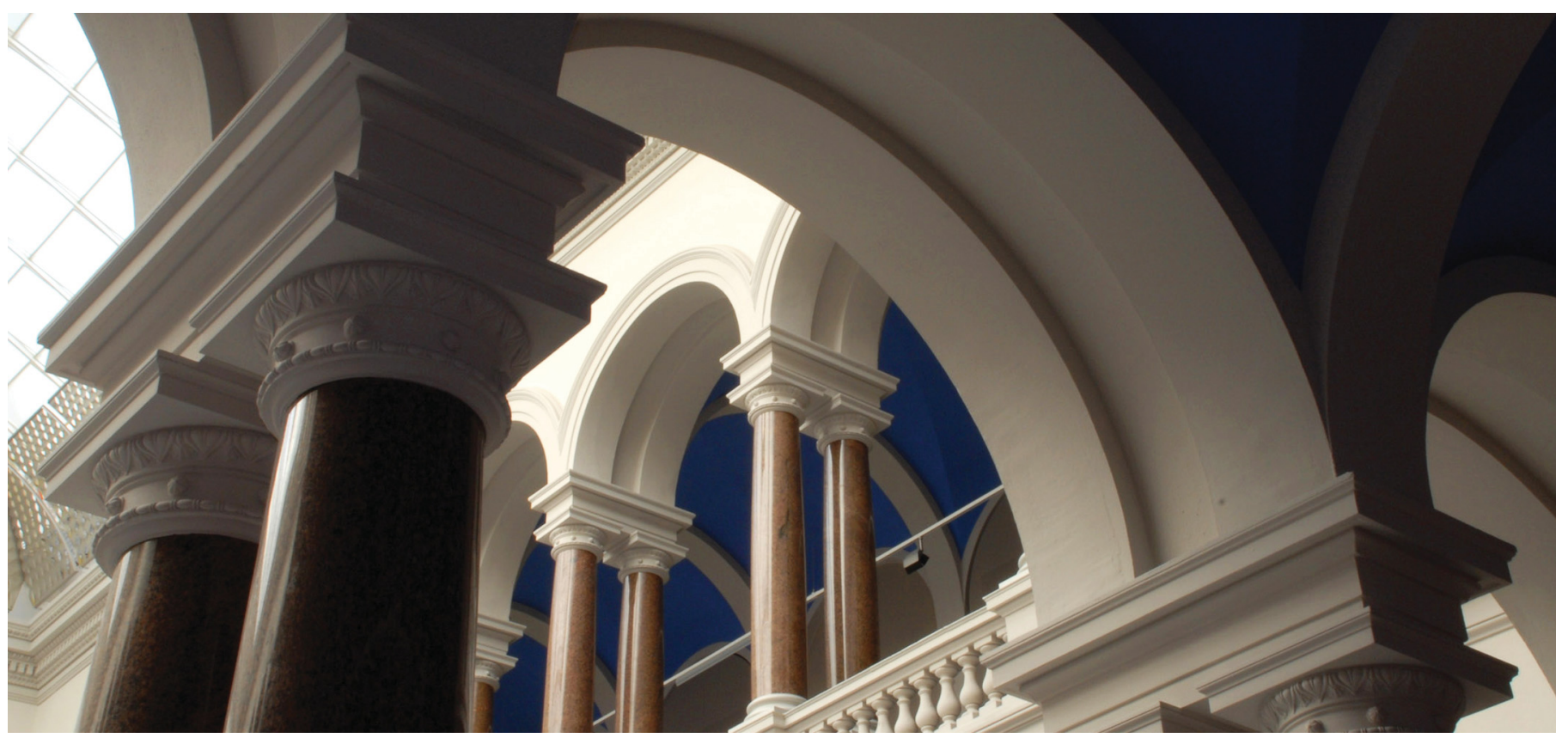

De Gregorio, Ludovica; Callegari, Mattia; Marin, Carlo; Zebisch, Marc; Bruzzone, Lorenzo; Demir, Begum; Strasser, Ulrich; Marke, Thomas; Gunther, Daniel; Nadalet, Rudi; Notarnicola, Claudia (2019). A Novel Data Fusion Technique for Snow Cover Retrieval. IEEE Journal of Selected Topics in Applied Earth Observations and Remote Sensing, 12(8), 2862-2877. https://doi.org/10.1109/jstars.2019.2920676 


\title{
A novel data fusion technique for snow cover retrieval
}

\author{
Ludovica De Gregorio ${ }^{1,2}$, Mattia Callegari ${ }^{1}$, Carlo Marin ${ }^{1}$, Marc Zebisch ${ }^{1}$, Lorenzo Bruzzone ${ }^{2}$, Begum Demir ${ }^{3}$, Ulrich Strasser ${ }^{4}$ \\ Thomas Marke ${ }^{4}$, Daniel Günther ${ }^{4}$, Rudi Nadalet ${ }^{5}$, Claudia Notarnicola $^{1}$ \\ ${ }^{1}$ EURAC Research, European Academy of Bozen / Bolzano, Institute for Earth Observation, viale Druso, 1-39100 Bolzano, Italy \\ ${ }^{2}$ University of Trento, Department of Information Engineering and Computer Science, Via Sommarive, 9, I-38123 Trento, Italy \\ ${ }^{3}$ Faculty of Electrical Engineering and Computer Science, Technische Universität Berlin, Straße des 17. Juni 135, 10623 Berlin, German \\ ${ }^{4}$ University of Innsbruck, Department of Geography, Innrain 52f, 6020 Innsbruck, Austria \\ ${ }^{5}$ Autonomous Province of Bolzano, Agency for Civil Protection - Hydrographic Office, viale Druso 116, 39100 Bolzano, Italy
}

\begin{abstract}
This paper presents a novel data fusion technique for improving the snow cover monitoring for a mesoscale Alpine region, in particular in those areas where the two information sources disagree.

The presented methodological innovation consists in the integration of remote sensing data products and the numerical simulation results by means of a machine learning classifier (Support Vector Machine), capable to extract information from their quality measures. This differs from the existing approaches where remote sensing is only used for model tuning or data assimilation. The technique has been tested to generate a time series of about 1300 snow maps for the period between October 2012 and July 2016.

The results show an average agreement between the fused product and the reference ground data of $96 \%$, compared to $90 \%$ of the MODIS data product and $92 \%$ of the numerical model simulation. Moreover, one of the most important results is observed from the analysis of snow cover area (SCA) time series, where the fused product seems to overcome the well know underestimation of snow in forest of the MODIS product, by accurately reproducing the SCA peaks of winter season.
\end{abstract}

Index Terms—Data fusion, snow model, machine learning, remote sensing, snow.

\section{INTRODUCTION}

$\mathrm{S}^{\mathrm{N}}$ NOW is a dynamically changing water resource that plays an important role in the hydrological cycle in mountainous areas. The traditional acquisition means for the snow cover distribution and variability are in-situ monitoring stations that provide point observations for their locations. The locations of most of these stations are in easily accessible and valley areas, whereas in the higher Alpine regions there are only few in operation, a notable exception, e.g., being the special observation networks of the national avalanche warning services. Therefore, in mountain regions, where the spatial variability of the snow cover is particularly high, the related hydrological processes are mostly unknown due to the lack of spatially and temporally continuous observations [1].

To fill this gap, remote sensing can make a valuable contribution by providing high spatial and temporal resolution data. Snow cover mapping by multispectral remote sensing images implies some limitations and problems. Sources of misinterpretation can be related to:

Clouds: one of the major problems in snow detection by satellite is the distinction between clouds and snow. Depending on the spectral channels available and cloud type, very bright reflectance of some clouds can make them indistinguishable from snow cover [2].

Forest cover: the reflectance of forested areas can be much lower than the one of non-forested areas, even with a considerable snowpack beneath the trees. The forest cover obscures the snow beneath and hence hides it from the optical sensors. Additionally, tree crowns intercept snow. Due to a higher crown density, conifer trees intercept considerably more snow than leafless deciduous trees and this affects the melting pattern as well as the accumulation pattern. Therefore, it is still a challenge to accurately detect the ground snow in a forested area [3].

Shadow: shadow can be particularly relevant in the winter season on north-facing slopes in dependence of the relative position between the sun and the sensor. Similarly, cloud shadows may complicate the snow detection process [4].

To reduce the effects of the cloud cover, a possible approach is to combine satellite images acquired at different times. In the case of MODIS satellites, Terra and Aqua composite images by Xie et al. [5] show a higher agreement with ground measurements than the daily Terra or Aqua product alone. Xie et al. applied their method to the Colorado Plateau (USA) and northern Xinjiang (China). 
For the 2003-2004 hydrological year, the daily Terra/Aqua composite images exhibit $\sim 10-15 \%$ less annual mean cloud cover and $\sim 1-4 \%$ more annual mean snow cover, compared to the daily Terra or Aqua products.

Parajka and Blöschl [6] and Gafurov and Bardoyy [7] added a temporal window to the Terra/Aqua data combination where 1 or to 2 days in the past and 1 or 2 days into the future were analyzed to produce cloud-free classification results.

New methods to improve the detection of snow under forests have been developed in recent years. Vikhamar and Solberg [8] for example applied a linear spectral mixing model for snow, trees and snow-free ground to calculate a fractional snow cover. The model requires a forest cover map and surface area proportions as input; the reflectance values of snow and forest are derived from in situ reflectance measurements. Wang et al. [9] introduced the Normalized Difference Forest Snow Index (NDFSI) to distinguish snow-covered from snow-free evergreen coniferous forests. The index is based on the analysis of the spectral signature of both landcover types in the near-infrared (NIR) and shortwave infrared (SWIR) bands.

In mountainous areas, shadows frequently occur on steep slopes when the sun elevation angles are low. Shaded areas generally have lower reflectance than sunny areas. Fahsi et al [10] demonstrated that, due to the effect of topography, satellite image pixels of the same cover type may have different spectral response, whereas pixels of different cover types may have similar spectral characteristics as well, due to the effect of topography. Therefore, many approaches have been proposed to remove, or at least to reduce the effect of topographic shadowing (topographic correction). Shahtahmassebi et al. [11] propose an alternative approach with respect to the conventional technique of cosine correction [12]. They tested two filling functions for estimating the forest areas in mountainous shadows in Landsat images using information about the land cover type of neighboring pixels. The drawback of this technique is the assumption of uniform variability of land cover type throughout the whole image during the interpolation phase. Moreover, this approach meets difficulties in complex landscapes where mixed pixels occur, especially at the forest borders. Another common approach to mitigate shadow effect is the multi-source data fusion. A simple and typical procedure, thereby, is to replace shadowed pixels in an image with the no-shadow pixels of the same area in a corresponding image acquired at different time [13]. Dorren et al. [14] used the multi-source approach by exploiting the digital elevation model (DEM) as additional band, in addition to Landsat TM data, to improve the forest mapping in steep mountainous terrain.

An alternative method for retrieving information about snow characteristic is the application of distributed, numerical snow models. These models use meteorological observations to simulate the accumulation, storage and melt of a seasonal snow cover. Many types of snow models, suitable for many different application purposes, have been developed, resulting in a wide variety of methodical simulation approaches, from purely empirical to more physically-oriented approaches [15]. Even though extensively tested and validated at well-equipped research sites, the complex energy-balance based models can be subject to rather large uncertainties if used in spatially distributed applications. These uncertainties may originate mainly from uncertainties in i) the meteorological input data, ii) snowpack process representations and iii) model parameter sets [16].

Due to the uncertainties in any single data source used to produce a snow cover map (data gaps, nonlinear dynamics or surface heterogeneity that make difficult parameters retrieval, model error and inaccurate processing algorithms), a single "best" remotelysensed data product or snow cover simulations result to monitor snow cover does not exist [17]. In this context, data fusion methods are a good alternative to overcome these limitations and exploit the strengths of the two different methods. In general, data fusion refers to a formal concept for combining data from different sources in order to provide new products of higher quality (in a broad sense) than the individual input datasets and thus to minimize the difference between true measurements and generated products. The most common use of this approach exploits information derived from spectral reflectivities provided by different terrestrial, airborne or satellite sensors. An example is the work done by Cammalleri et al. [18], who proposed a new approach for evapotranspiration (ET) retrieval. Since satellite-based thermal sensors are characterized by either low spatial resolution and high repeatability or by moderate/high spatial resolution and low frequency, they fused characteristics of both classes of sensors, by exploiting daily MODIS images at $1 \mathrm{~km}$ and biweekly Landsat imagery at $30 \mathrm{~m}$, to provide optimal spatiotemporal coverage.

In literature, only few works perform a real data fusion between remote sensing and model products. Painter et al. [19] combined results from the Airborne Snow Observatory (ASO), a coupled scanning lidar system and imaging spectrometer, with a distributed snow model in order to obtain the snow spectral/broadband albedo and the snow water equivalent (SWE). First, spectrometer data have been fused with lidar data and then combined with the snow model simulations in order to obtain a higher-level product, such as the SWE, that is retrieved from the combination of lidar-derived snow height ([20], [21]) and modeled snow density.

The most common approach for using snow cover simulation together with remote sensing data in a synergistic way is involving the latter in a data assimilation approach or in the calibration phase. Data assimilation techniques have undergone continuous development in the last decades: in weather forecasting, the assimilation of satellite, atmospheric and surface observations into numerical weather prediction (NWP) models has led to an extreme improvement in the forecast skill [22]. The data assimilation techniques have also been developed and implemented in many other applications from hydrology ([23], [24]) to biogeochemistry ([25], [26]). However, dynamical incorporation of remotely sensed data into any model systems is not a trivial task and is computationally expensive. Finger et al. [27] proposed a multiple data set calibration approach to estimate runoff composition using hydrological models with three levels of complexity. The results indicate that all three observational data sets are reproduced adequately by the model, allowing an accurate estimation of the runoff in the three mountain streams.

The objective of this study is to develop a novel fusion approach for snow cover maps generation by using physically-based model simulations and remotely sensed products. The fusion aims at improving the snow cover detection in those areas where data sources 
disagree. As such, we try to overcome the aforementioned limitations of traditional methods and to take advantage of both the specific properties of remote sensing data (such as detailed spatial representation of the estimated parameters), and of the physical basis (independency from atmospheric and shadowing conditions) of the model simulations. The proposed fusion approach is based on a Support Vector Machine (SVM), a machine learning technique which has many important properties relevant for the analysis of remotely sensing data (i.e. high generalization capability, relatively high accuracy, sparsity of the solution and fast processing in the test phase [28]). Moreover, due to the minimization of the structural risk, it is more robust than other pattern recognition techniques in training datasets with a small number of labeled samples.

The innovative aspect of the presented approach is the joint exploitation of remotely sensed data and physical model results, differing from approaches where remote sensing is mainly used for model tuning. In the decision-level fusion process, the snow cover maps and their quality measures are retrieved separately from the two different sources, then they are integrated by SVM to exploit their complementarities and to address their uncertainties.

The final output of this research is a time series of about 1300 fused snow maps obtained by applying the method to the whole simulation period (October 2012 - July 2016).

The paper is organized as follows: after introducing the study area and datasets in section 2, the method for data fusion is described in section 3; results are shown and discussed in section 4 and, finally, conclusions on current applicability and indications for future development are drawn in section 5 .

\section{STUDY AREA AND DATASET}

\section{A. Study Area}

The study area of this research is the area including Tyrol (Austria), South Tyrol (Italy) and Trentino (Italy) (Fig. 1). This area is a good field laboratory because it is well instrumented and this guarantees a high data availability. The climatological conditions are representative for different Alpine zones: precipitation reaches its maximum in the northern and southern prealpine areas (up to $2200 \mathrm{~mm} /$ year), whereas the inner region is drier (less than $600 \mathrm{~mm} /$ year in the Venosta region) [29]. Permanent snow line ranges between 3200 and $2800 \mathrm{~m}$ a.s.l. Most of the rivers in the central and northern part of the region considered have a nivoglacial regime with maximum discharge during the later summer months, whereas in the southern part of Trentino maximum discharge is usually found during spring or fall with an earlier snowmelt [30]. The region is covered by a dense network of meteorological and snow monitoring stations, operated by the Hydrographical Services of the regional authorities, which provide an excellent validation dataset for the proposed methodologies.

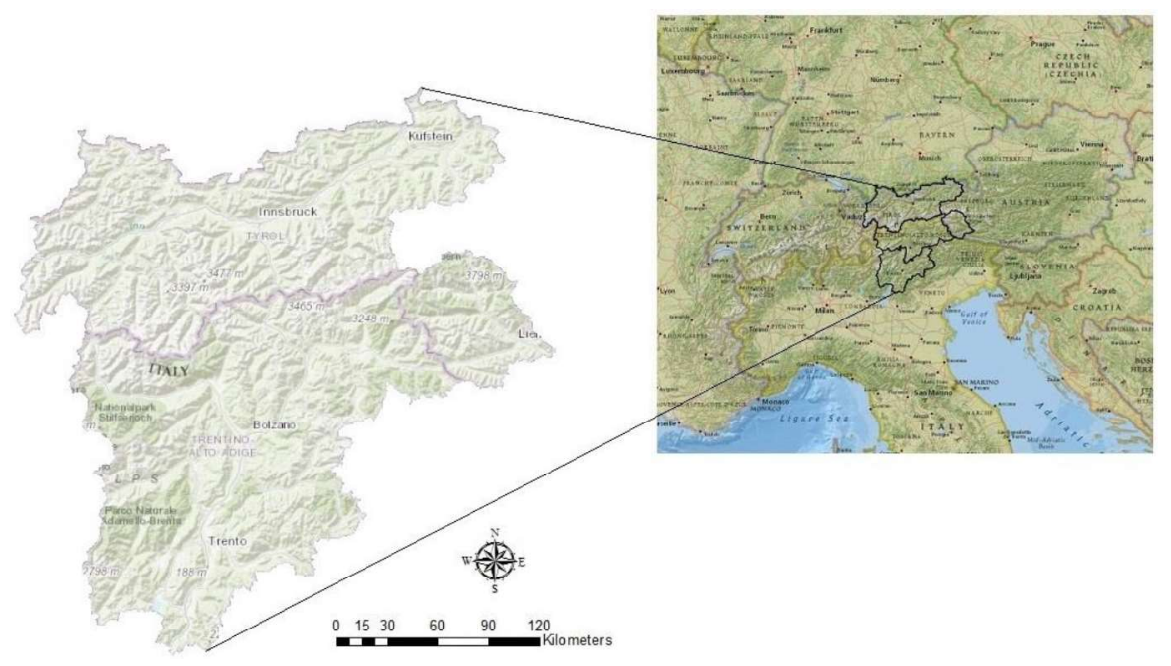

Fig. 1. Study area: Tyrol (Austria), South Tyrol (Italy) and Trentino (Italy).

\section{B. Data Description}

The fusion method adopted in this study involves the use of snow maps and respective quality measures, originating independently from satellite remote sensing data and from distributed, numerical snow model simulations (table 1). 
TABLE I

THE DATA SOURCES USED FOR THE PRESENTED SVM FUSION APPROACH

\begin{tabular}{|c|c|c|c|c|}
\hline Type & \multicolumn{2}{|c|}{ Source } & Resolution & Use \\
\hline $\begin{array}{c}\text { Snow cover } \\
\text { maps+ } \\
\text { quality measure }\end{array}$ & $\begin{array}{l}\text { Remote } \\
\text { sensing }\end{array}$ & $\begin{array}{l}\text { EURAC } \\
\text { MODIS }\end{array}$ & $\begin{array}{l}\text { Spatial: } 250 \mathrm{~m} \\
\text { Temporal: dalily }\end{array}$ & $\begin{array}{l}\text { Input data for } \\
\text { data fusion } \\
\text { approach }\end{array}$ \\
\hline \multirow{2}{*}{$\begin{array}{c}\text { Snow cover } \\
\text { maps }\end{array}$} & \multirow{2}{*}{$\begin{array}{l}\text { Remote } \\
\text { sensing }\end{array}$} & Sentinel 2 & $\begin{array}{l}\text { Spatial: } 10 \mathrm{~m} \text { (optical } \\
\text { bands) } \\
\text { Temporal: } 12 \text {-days }\end{array}$ & \multirow{2}{*}{$\begin{array}{l}\text { Reference } \\
\text { dataset }\end{array}$} \\
\hline & & Landsat 8 & $\begin{array}{l}\text { Spatial: } 30 \mathrm{~m} \\
\text { Temporal: } 16 \text {-days }\end{array}$ & \\
\hline $\begin{array}{c}\text { Snow cover } \\
\text { maps+ } \\
\text { quality measure }\end{array}$ & \multicolumn{2}{|c|}{$\begin{array}{l}\text { Hydrological Model } \\
\text { (AMUNDSEN) }\end{array}$} & $\begin{array}{l}\text { Spatial: } 250 \mathrm{~m} \\
\text { Temporal: daily }\end{array}$ & $\begin{array}{l}\text { Input data for } \\
\text { data fusion } \\
\text { approach }\end{array}$ \\
\hline $\begin{array}{l}\text { Ground data } \\
\text { (snowheight) }\end{array}$ & \multicolumn{2}{|c|}{ Manual measurements } & $\begin{array}{c}\text { Temporal:weekly/bi- } \\
\text { weekly }\end{array}$ & $\begin{array}{l}\text { Dataset for } \\
\text { validation }\end{array}$ \\
\hline
\end{tabular}

1) Remote Sensing Data: In this study two types of satellite data-derived products have been used:

- MODIS snow maps developed by Eurac Research.

- Sentinel-2 and Landsat-8 RGB images.

The MODIS images, which are freely provided by NASA (http://modis.gsfc.nasa.gov/), have been processed by Eurac Research (Bolzano, Italy) by applying a specific algorithm adapted to mountain areas to obtain snow maps with $250 \mathrm{~m}$ spatial resolution ([31], [32]). The spatial resolution higher than the standard MODIS product (which has $500 \mathrm{~m}$ spatial resolution) can better represent the snow variability in mountainous terrain with very complex topography. The MODIS product derived from the algorithm has been extensively validated by comparison with high resolution SCA maps derived from Landsat 7 ETM+ images, with the NASA standard SCA products MOD10 (MYD10) and with snow height measured by ground stations in selected test sites in Austria, Slovakia, Germany and Italy [32]. Overall accuracies for the different regions between the Eurac SCA product and in situ snow measurements range between $82.4 \%$ and $93.7 \%$. The comparison with Landsat shows a mean overall accuracy of around $88.1 \%$ in forested areas, whereas in open areas the accuracy reaches $93.6 \%$. The same behavior was found in the comparison with the NASA product, where the accuracy is $90.2 \%$ and decreases to $85.4 \%$ in forested areas [33]. In open areas the performances are quite similar, with the advantage that more detailed features are detectable with respect to the 500 m MOD10 (MYD10) maps. All snow maps are provided together with a quality measure, which is based (as explained in the following section relative to the "Data collection") on NDSI. This index, unlike the standard MODIS product, is not used for snow cover area estimation and thus can be used for estimating a quality layer. Further details about the algorithm are explained in [31]. These snow maps, together with the quality measure, have been used as inputs to the fusion process.

The high-resolution images provided by Sentinel-2 and Landsat- 8 have been used for extracting reference values used in the training phase of the data fusion classifier. For this purpose, RGB images (with a spatial resolution of 10 and $30 \mathrm{~m}$ for Sentinel-2 and Landsat-8, respectively) have been used in a visual interpretation to find suitable reference points. Unlike the MODIS dataderived snow maps that are available daily, Sentinel-2 mission consists of two satellites flying on the same orbit but phased at $180^{\circ}$, which have a revisit frequency of 5 days at the Equator. The temporal resolution of Landsat- 8 is instead 16 days. Thus, the selection of dates for extracting the reference points has been constrained by the availability of Sentinel-2 and Landsat- 8 images.

2) Snow cover simulations: The evolution of the seasonal snowpack is simulated with the distributed, physically-based hydroclimatological model framework "Alpine MUltiscale Numerical Distributed Simulation Engine" (AMUNDSEN) [33]. For every time step and grid cell, a meteorological preprocessor computes all necessary inputs to solve the coupled mass and energy balance of the snowpack and does not require any calibration. The functionality of the model includes sophisticated routines for (i) the regionalization of meteorological input data of various sources [34], (ii) the simulation of short- and longwave radiation including the consideration of shadows and cloudiness [35], (iii) the simulation of the snowpack thermodynamics by means of the factorial snowpack model (FSM) [36] and (iv) the simulation of canopy effects between the trees and snow accumulation on the ground ([37], [38]). The presented study focusses on snow cover mapping, hence the model set-up is limited to simulate the snowpack evolution and any processes subsequent to snow melt are neglected (e.g. no simulation of stream flow).

Snow cover simulations are forced with hourly recordings of air temperature, precipitation, global radiation, wind speed and humidity from 325 climate stations in the regions. Furthermore, AMUNDSEN requires a digital elevation model and maps of land use, soil properties and watershed delineation as inputs in order to distribute input meteorology and parameter sets across the simulation domain.

AMUNDSEN has proven its performance in a variety of applications in most different natural environments [39]. The model ability to predict the seasonal snowpack accumulation and ablation processes in the region was validated at 38 stations with automated snow height recordings. Additionally, 16 stations operated by the hydrographic service of the province Bolzano provide recordings of snow surface temperature, offering the opportunity to validate the mass and energy balance separately. Generally, daily snow height was predicted with acceptable accuracy with a mean Nash-Sutcliffe efficiency (NSE) of 0.68 (ranging from 0.25 
to 0.96$)$. However, especially at stations prone to significantly lateral fluxes of blowing snow the observed snow height dynamic could not be reproduced accurately. We explain this primarily by the precipitation under catch corrections, which are well performing at most stations in the region but fail under such extreme conditions. Surface temperature observations could be reproduced with a mean NSE of 0.88 , indicating that the model is well capable of solving the energy balance of the snowpack.

3) Ground Data: The ground measurements of snow height, used for validating our results, are collected through different procedures depending on the region. In South Tyrol, measurement campaigns are carried out every day, at 7 a.m., during the whole winter season (from October to May) by private citizens appointed by the public administration. The objective of the survey is to characterize the day from a nivometeorological point of view through a series of significant parameters that can be extracted with simple and fast procedures. The measurements concern parameters such as: snowpack height, fresh snow height, air temperature, weather conditions, cloudiness, visibility and wind activity at high altitude. In particular, for the snow height measurement, a snow measurement stick is inserted vertically into the snowpack until the bottom of the stick rests on the ground; the total height of the snowpack is read on the graduated scale, at the surface of the snowpack.

The measurement sites should be representative of the surrounding area from a nivological point of view, i.e. with regular snow deposition and snowpack evolution by avoiding zones with too fast changes due to the action of wind. The ideal terrain for measurement sites is a flat or slightly sloping terrain $\left(<10^{\circ}\right)$. The data have been provided by the Autonomous Province of Bolzano, Agency for Civil Protection - Hydrographic Office.

In Trentino, snow height data have been collected from the snow profiles weekly performed by the operators of the Avalanche Office of Province of Trento, alpine guides or avalanche commission members. During the campaign a snow profile is carried out by the operators who analyze and extract parameters which help to identify weaknesses and processes in the snowpack for an avalanche risk evaluation. The extracted parameters are snow height, snow density, grain size and shape for each snowpack layer and air temperature. The data have been provided by Autonomous Province of Trento - Risk prevention service, Forecasting and planning office. Finally, regarding Tyrol, data have been collected from some automatic nivometeorological stations and provided by the Hydrographic Service of Tyrol. Fig. 2 shows the measurement sites location in the test area.

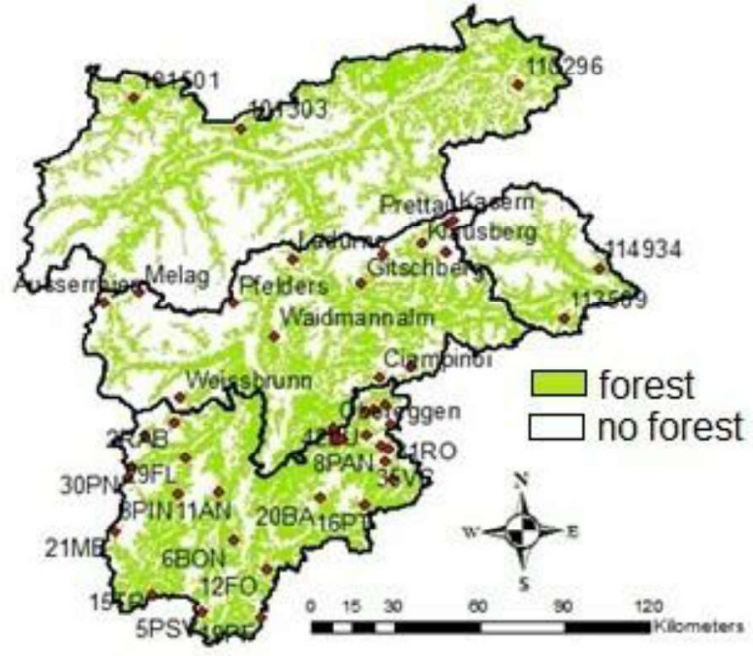

Fig. 2. Location of measurement sites in the test region. In Tyrol the measurement sites are indicated with numbers, in South Tyrol with the name of location and in Trentino with alphanumeric codes. For reproducibility of the analysis, the stations names have been simply reported as provided by the Province databases.

\section{METHOD}

The aim of the proposed fusion approach is to improve the snow cover mapping in the areas where remote sensing product and the simulation results disagree, by taking advantage of both the specific properties of remote sensing data (such as detailed spatial representation of the estimated parameters) and the characteristics typical of physical model (such as solid physical basis and good generalization capabilities). The satellite data-derived snow maps and the model-simulated snow distribution are considered as independent data sets, with individual, spatially varying accuracy. Hereafter, the snow maps derived from the satellite data and those derived from the model simulations will be called MODIS and AMUNDSEN products, respectively.

In the next sections the method for quality measure computation will be explained and later the fusion strategy is presented.

\section{A. Computation of Quality Measures}

The first step of the proposed method consists in the calculation of the quality measures of the two snow cover maps, provided by remote sensing and snow model simulations, respectively. The techniques for the calculation of these quality measures, which are later used as input together with the snow maps for the classifier, are explained in the following sections. 


\section{1) Quality Measure for the MODIS Product}

The quality measure for the MODIS product is based on NDSI (Normalized Difference Snow Index). It is computed only for the two classes of interest, i.e. snow and no snow, whereas for all the other classes it is not considered. NDSI is an index related to the presence of snow in a pixel and is based on the different reflectivity values of the surface between a band in the visible and one in the short-wavelength infrared (or near-infrared) parts of the spectrum. Since snow is highly reflective in the visible bands and highly absorptive in the short-wavelength infrared (or near-infrared), this index allows a good distinction between snow and clouds, most of which have a high reflectivity in both sections of the spectrum.

$$
N D S I=\frac{V I R-S W I R}{V I R+S W I R} \quad \rightarrow \quad-1 \leq N D S I \leq 1
$$

One of the main differences between the Eurac and NASA algorithms in the detection of snow is the use of NDSI index (bands for this index are at $500 \mathrm{~m}$ ). The NASA algorithm adopts a combined use of NDVI and NDSI, which improves the snow detection in forested areas. Vice versa, the Eurac algorithm uses only the NDVI and B1 (the blue band) to preserve the resolution of $250 \mathrm{~m}$. This allows us to use the NDSI for assessing the quality of the snow classification in each pixel. For the snow and no snow classes, the quality measure (U) can vary between 0 (low quality) and 1 (high quality) and is computed as follows:

$$
\left\{\begin{array}{c}
U=\frac{1+N D S I}{2} \text { for the class snow } \\
U=\frac{1-N D S I}{2} \text { for the class no snow }
\end{array}\right.
$$

\section{2) Quality Measure for the AMUNDSEN Product}

Snow maps derived from physically-based model simulations comprise a large number of state variables for the snow pack in each pixel. First, however, we only use the binary information of snow presence (i.e., whether snow is present in a certain pixel, or not) for the processing of the snow maps. These are derived from simulated snow water equivalent (SWE):

$$
\left\{\begin{array}{c}
\text { if } \quad S W E<t h \rightarrow x=0(\text { snowfree }) \\
\text { if } S W E>t h \rightarrow x=1(\text { snowcovered })
\end{array}\right.
$$

Where $t h=5 \mathrm{~mm}$ is a threshold that accounts for the scale discrepancy between a point location and the pixel dimension. The resulting map is a binary image with values being 0 (no snow) or 1 (snow).

The quality measure for the AMUNDSEN product is computed in two different ways for snow-covered and snow-free pixels. The quality measure for snow covered pixels is very simplistic and merely links the uncertainty information of the pixels to the magnitude of predicted SWE value. The assumption behind this approach is that, due to the cumulative nature of the snowpack, large errors (in total snow mass) are needed for a misclassification of snow-covered pixels when a deep snowpack is predicted, whereas smaller errors in snow mass suffice for a misclassification when a shallow snowpack is predicted. The certainty of the classification is assumed to increase with increasing snow mass in a hyperbolic manner. For deep snowpack far enough away from the snow cover threshold, an increase in snow mass is assumed to not further increase the certainty of the snow cover classification. Starting from these definitions, the quality measure for snow-covered pixels is calculated considering that a higher quality in the snow map is associated with a larger snow mass and, thus, a larger SWE value:

$$
U=-\tanh \left(\frac{S W E}{S W E_{t}}\right)+1
$$

with $S W E_{t}=100 \mathrm{~mm}$ and $S W E$ the snow water equivalent value of the pixel.

For snow-free pixels, the quality of the snow cover classification is assumed to increase over time until a threshold is reached: the higher the number of previous snow-free days, the higher is the probability that the pixel is snow-free. This quality approximation relies on the time distance to the predicted melt out of a cell. Errors in the simulation of accumulation and ablation processes will translate to error in melt-out timing. With an increasing time distance to the predicted melt-out, larger model errors would be required for a misclassification. In order to maintain a reasonable scaling of the quality measure, the growth of the certainty is limited. Otherwise the certainty of a no-snow classification in autumn would be unrealistic high compared to one just after the snow ablation in spring. The respective quality measure hence is:

$$
U=-\tanh \left(\frac{\Delta t}{\Delta t_{t}}\right)+1
$$

with $\Delta t_{t}=10$ days and $\Delta t$ the number of no-snow days.

The quality measures as defined here can be considered as proxy quantities of the model accuracies for the detection of snow and snow-free pixels. 


\section{B. Data Fusion Strategy}

The fusion strategy involves the disagreement points through the use of SVM technique and exploiting as input features the snow maps from MODIS and from model simulations, as well as the relative quality measures.

The procedure is summarized in Fig. 3. It includes three phases:

- Data collection: MODIS and AMUNDSEN snow maps, together with their quality measures are prepared to be then used as inputs to the data fusion process. The MODIS snow maps considered are of binary type (snow/no-snow), with other classes (clouds, water and no-data) masked. Simultaneously, high-resolution RGB images from Sentinel-2 and Landsat-8 acquired during the period October 2012 - July 2016 are selected and collected.

- Data selection and SVM training: the input data and the corresponding reference data has been selected for the estimation of the SVM model parameters during the training phase. Since the dataset for performance evaluation in the testing phase shall be independent, two datasets (one for training and one for testing the classifier) have been collected: the first step was the selection of some dates in different periods of the year, in order to consider the seasonal variability of snow coverage. Then, on these randomly selected dates, the pixels locations have been selected and extracted from the snow maps. The corresponding reference dataset with the true labels has been extracted through a visual interpretation of S2 and L8 images and the whole data set created. This resulting dataset was then randomly divided into a training dataset ( $80 \%$, about 720 points) and a test dataset ( $20 \%$, about 180 points).

- Maps generation and performance evaluation: finally, the classifier has been tested on the independent dataset (test dataset) to evaluate the performance.

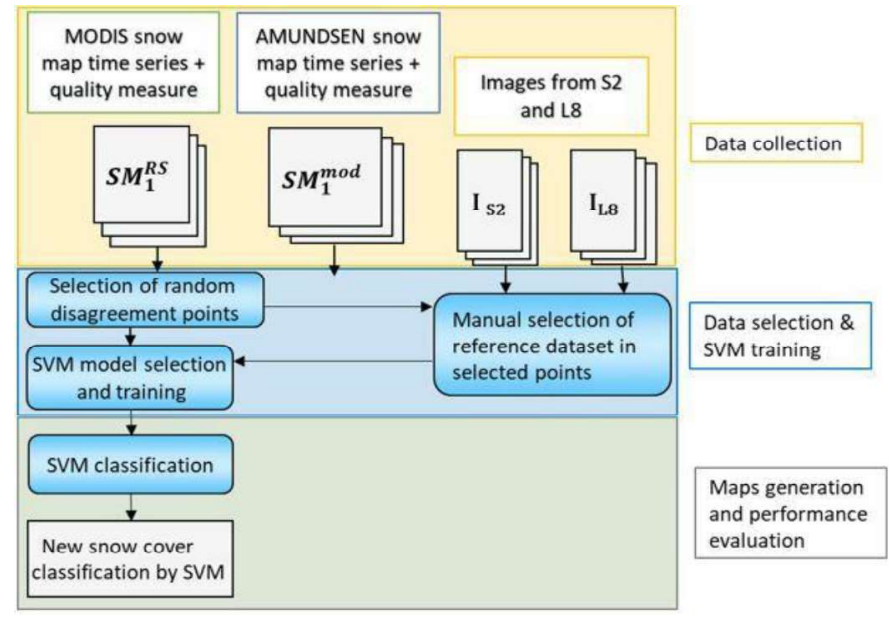

Fig. 3. Data fusion strategy flowchart.

\section{Support Vector Machine Approach}

SVMs are supervised learning models for classification and regression procedures. They can address both linear and non-linear relations and work well for many practical applications. SVMs have been proved to have a higher classification accuracy than other widely used pattern recognition techniques, such as the maximum likelihood and the multilayer perceptron neural network classifiers [28]. Moreover, SVMs appear to be especially advantageous when only few training samples are available [28].

An important property of SVM models is that they do not require the knowledge of the statistical distributions of classes to carry out the classification, as they exploit the concept of margin maximization [28]. The growing interest in SVMs is mainly related to a) the higher effectiveness with respect to traditional classifiers, resulting in high classification accuracies and very good generalization capabilities; b) the relatively low effort required for architecture design (only few control parameters); c) applicability to linearly constrained quadratic optimization problems.

These described properties, together with a strong ability to deal with remotely sensed data [28], make SVM the suitable approach to address the presented classification problem. Further technical details on SVM mathematical formulation can be found in [28].

\section{Validation Strategy}

The validation of the data fusion method has been conducted at two different levels: the first one exploits the data from highresolution remotely sensed images, whereas the second considers the ground data collected by measurement sites located throughout the test area.

In order to compare snow height ground measurements with the binary maps (snow or no-snow) obtained from the fusion approach, as well as those derived by both MODIS and AMUNDSEN, a threshold needs to be selected for discriminating between snow and no-snow. Two different threshold values on snow height, i.e. $5 \mathrm{~cm}$ and $10 \mathrm{~cm}$, were tested to assess the impact of this choice on results. 
As shown by Thyrel et al. [40], the agreement with ground data seems to improve for lower snow height threshold. Other snow height threshold values have been used in literature, such as $1 \mathrm{~cm}$ [41], $2.54 \mathrm{~cm}$ [42] and [43], $2 \mathrm{~cm}$ [32]. The final choice of setting $5 \mathrm{~cm}$ as threshold is related to the observation that a shallow snow layer can rapidly melt during the day and might thus not reveal the actual snow status at the time of the satellite acquisition. Vice versa, a too low threshold may not be representative of the surrounding area.

The validation with ground data has been carried out by using points that are, except some cases, snow-covered, since the snow height measurements are performed in winter season and manual observations for snow-free conditions are lacking.

\section{RESUlTS AND DisCUSSION}

In this section, the validation of the proposed method and the results derived from the analysis of time series are presented. Hereafter, in the validation with ground data, the term "points" indicates the single ground data at a specific date and in a specific observation site.

\section{A. Validation with High-Resolution Images}

By validating the fusion data method on the test dataset (180 points), the overall accuracy reaches $89 \%$, with respect to $40 \%$ (MODIS) and 60\% (AMUNDSEN). Fig. 4 shows the confusion matrices and some statistical indices for the test points. The overall accuracy $(\mathrm{OA}$, in \%) is defined as the sum of snow/snow agreement and no-snow/no-snow agreement divided by the total number of observations available. The True Positive Rate (TPR) indicates the percentage of snow samples that are correctly identified and the True Negative Rate (TNR) represents the proportion of no-snow points that are correctly identified.

\begin{tabular}{|c|c|c|}
\hline MODIS & No_snow & Snow \\
\hline No_snow & 1 & 38 \\
\hline Snow & 69 & 71 \\
\hline
\end{tabular}

a)

$$
\begin{gathered}
\mathrm{OA}=0.40 \\
\mathrm{TPR}=0.65 \\
\mathrm{TNR}=0.01
\end{gathered}
$$

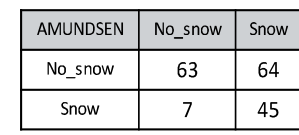

b)

$\mathrm{OA}=0.60$
$\mathrm{TPR}=0.41$
$\mathrm{TNR}=0.90$

\begin{tabular}{|c|c|c|}
\hline Fused product & No_snow & Snow \\
\hline No_snow & 61 & 11 \\
\hline Snow & 9 & 98 \\
\hline
\end{tabular}

c)

$$
\begin{gathered}
\mathrm{OA}=0.89 \\
\mathrm{TPR}=0.90 \\
\mathrm{TNR}=0.87
\end{gathered}
$$

Fig. 4. Confusion matrix relative to a) MODIS product; b) AMUNDSEN product; c) fused product. OA= Overall Accuracy; TPR= True Positive Rate; TNR= True Negative Rate.

From the confusion matrices, it results that, on average, the MODIS product tends to overestimate the snow coverage while the AMUNDSEN product seems to underestimate it. The new fused product balances these behaviors by improving the overall accuracy with the high-resolution images.

Table 2 shows the agreement with reference dataset divided per area, as fraction of total points matching with the selected points in high-resolution images. The three products, i.e. MODIS, AMUNDSEN and fused products, are reported separately for the three areas. The column "Points per area" indicates the total number of points selected for South Tyrol, Trentino and Tyrol, respectively.

\begin{tabular}{|c|c|c|c|c|}
\hline Area & MODIS & AMUNDSEN & FUSED & $\begin{array}{l}\text { Points per } \\
\text { area }\end{array}$ \\
\hline \multirow[t]{2}{*}{ SOUTH TYROL } & $\%$ of agreement & $\%$ of agreement & $\%$ of agreement & \\
\hline & $39 \%$ & $69 \%$ & $88 \%$ & 60 \\
\hline \multirow[t]{2}{*}{ TRENTINO } & $\%$ of agreement & $\%$ of agreement & $\%$ of agreement & \\
\hline & $35 \%$ & $56 \%$ & $90 \%$ & 60 \\
\hline \multirow[t]{2}{*}{ TYROL } & $\%$ of agreement & $\%$ of agreement & $\%$ of agreement & \\
\hline & $47 \%$ & $55 \%$ & $88 \%$ & 59 \\
\hline
\end{tabular}

Results indicate that AMUNDSEN shows a higher agreement with selected reference points in South Tyrol with respect to the other areas; vice versa, MODIS seems to perform better in Tyrol than in South Tyrol and in Trentino.

TABLE 2

AGREEMENT (\%) FOR EACH AREA (SOUTH TYROL, TRENTINO AND TYROL) WITH VALIDATION POINTS EXTRACTED FROM HIGH-RESOLUTION IMAGES

\section{B. Validation with Ground Data}

For the second type of validation analysis we compare the data fusion product to ground data. The general results are shown in

Fig. 5, where the confusion matrices for the three products are reported.

Fig. 5 shows the same behavior found in Table 2: MODIS has the best performances in Tyrol, whereas AMUNDSEN accuracy is higher for South Tyrolean territory. 
SOUTH TYROL

\begin{tabular}{|l|c|c|}
\hline MODIS & No_snow & Snow \\
\hline No_snow & 70 & 230 \\
\hline Snow & 19 & 49 \\
\hline \multicolumn{3}{|c|}{\begin{tabular}{c} 
O.A. $=0.32$ \\
T.P.R. $=0.18$ \\
T.N.R. $=0.79$ \\
\hline
\end{tabular}}
\end{tabular}

\begin{tabular}{|c|c|c|}
\hline AMUNDSEN & No_snow & Snow \\
\hline No_snow & 19 & 49 \\
\hline Snow & 70 & 230 \\
\hline \multicolumn{2}{|c|}{$\begin{array}{c}\text { O.A. }=0.68 \\
\text { T.P.R. }=0.82 \\
\text { T.N.R. }=0.21\end{array}$} & \\
\hline
\end{tabular}

\begin{tabular}{|c|c|c|}
\hline Fused_product & No_snow & Snow \\
\hline No_snow & 39 & 43 \\
\hline Snow & 50 & 236 \\
\hline \multicolumn{2}{|c|}{ O.A. $=0.75$} \\
T.P.R. $=0.85$ \\
T.N.R. $=0.44$ \\
\hline
\end{tabular}

TRENTINO

\begin{tabular}{|l|c|c|}
\hline MODIS & No_snow & Snow \\
\hline No_snow & 0 & 20 \\
\hline Snow & 0 & 20 \\
\hline \multicolumn{3}{|c}{$\begin{array}{c}\text { O.A. }=0.50 \\
\text { T.P.R. }=0.5 \\
\text { T.N.R. }=1 \\
\end{array}$} \\
\hline
\end{tabular}

\begin{tabular}{|c|c|c|}
\hline AMUNDSEN & No_snow & Snow \\
\hline No_snow & 0 & 20 \\
\hline Snow & 0 & 20 \\
\hline \multicolumn{3}{|c|}{$\begin{array}{c}\text { O.A. }=0.50 \\
\text { T.P.R. }=0.5 \\
\text { T.N.R. }=1 \\
\end{array}$} \\
\end{tabular}

\begin{tabular}{|c|c|c|}
\hline Fused_product & No_snow & Snow \\
\hline No_snow & 0 & 0 \\
\hline Snow & 0 & 40 \\
\hline \multicolumn{3}{|c|}{\begin{tabular}{c} 
O.A. $=1$ \\
T.P.R. $=1$ \\
T.N.R. $=$ / \\
\hline
\end{tabular}} \\
\hline
\end{tabular}

TYROL

\begin{tabular}{|l|c|c|}
\hline MODIS & No_snow & Snow \\
\hline No_snow & 19 & 22 \\
\hline Snow & 28 & 64 \\
\hline \multicolumn{3}{|c|}{$\begin{array}{c}\text { O.A. }=0.62 \\
\text { T.P.R. }=0.74 \\
\text { T.N.R. }=0.40 \\
\end{array}$}
\end{tabular}

\begin{tabular}{|c|c|c|}
\hline AMUNDSEN & No_snow & Snow \\
\hline No_snow & 28 & 64 \\
\hline Snow & 19 & 22 \\
\hline
\end{tabular}

\begin{tabular}{|c|c|c|}
\hline Fused_product & No_snow & Snow \\
\hline No_snow & 30 & 20 \\
\hline Snow & 17 & 66 \\
\hline \multicolumn{3}{|c|}{\begin{tabular}{|l} 
O.A. $=0.72$ \\
T.P.R. $=0.77$ \\
T.N.R. $=0.64$ \\
\hline
\end{tabular}}
\end{tabular}

Fig. 5. Validation with ground data. Confusion matrix relative to a) MODIS product; b) AMUNDSEN product; c) fused product. OA= Overall Accuracy; $\mathrm{TPR}=$ True Positive Rate; TNR= True Negative Rate.

By using a threshold value of $5 \mathrm{~cm}$, the agreement percentages for each observation are calculated for all three snow cover maps (table 3). The column "Points per station" indicates the number of points available for each station. The agreement percentages have been evaluated by considering the number of points, which can vary considerably among the observation sites. This could lead to different performances: in most of Trentino site, for example, the number of available measurements may be very low (in the worst case only 2 measurements are available) so the percentages may also be very high. If the measurement site is located in a pixel classified as "cloud" in MODIS product, it is excluded from the analysis.

The average agreement between the fused product and observations is $96 \%$ with respect to $90 \%$ (MODIS) and to $92 \%$ (AMUNDSEN) (Table 3).

In this type of validation, ground data can involve both pixels where MODIS and AMUNDSEN disagree and where they agree. Since the fusion process is applied only on disagreement pixels, in order to assess how the method works, some statistics have been computed by considering only these points, i.e. where AMUNDSEN indicates "snow" and MODIS "no-snow" (or vice versa).

Fig. 6 presents the results about the validation in South Tyrol: for each measurement site the two columns indicate on the left the AMUNDSEN and MODIS behavior and on the right the fused product behavior. White bars represent the number of total available points (dates) for each measurement site; light and dark blue respectively show the samples where MODIS is wrong and AMUNDSEN is correct with respect to the ground data and vice versa. Above these two bars, the cyan bars indicate the points where both model and satellite data are wrong. The remaining points above the cyan bars are the points where AMUNDSEN and MODIS agree and give correct classification. In these points, as well as in the points of cyan bars, the fusion does not work because the model and the satellite products agree. For each measuring site, the sum of pink bars gives an idea of the improvement provided by the presented approach with respect to the single sources (MODIS and the AMUNDSEN snow maps), by showing the number of disagreement points that are correctly classified after fusion approach.

By averaging the results on all the stations, one can observe that $76 \%$ of the disagreement points are correctly classified by the SVM classifier. Moreover, in about $73 \%$ of these correctly classified points, the fused product follows AMUNDSEN, while in the remaining $27 \%$ it coincides with MODIS. 
TABLE 3

AgREEMENT (\%) FOR EACH MEASURING STATION IN SOUTH TYROL, IN TRENTINO AND IN TYROL. IN TRENTINO, ONLY 12 OUt OF 28 STATIONS HAVE AT LEAST ONE POINT OF DISAGREEMENT BETWEEN MODIS AND AMUNDSEN. IN THE TABLE, ONLY THESE STATIONS ARE MENTIONED, OMITTING ALL THOSE WHERE AMUNDSEN AND MODIS ARE ALWAYS IN AGREEMENT.

\begin{tabular}{|c|c|c|c|c|}
\hline Station name & MODIS & Model & FUSED & $\begin{array}{l}\text { Points per } \\
\text { station }\end{array}$ \\
\hline SOUTH TYROL & $\%$ of agreement & $\%$ of agreement & $\%$ of agreement & \\
\hline Ausserrojen & $96 \%$ & $94 \%$ & $95 \%$ & 182 \\
\hline Ciampinoi & $98 \%$ & $99 \%$ & $99 \%$ & 241 \\
\hline Gitschberg & $97 \%$ & $86 \%$ & $99 \%$ & 127 \\
\hline Kasern & $77 \%$ & $89 \%$ & $88 \%$ & 191 \\
\hline Klausberg & $49 \%$ & $99 \%$ & $87 \%$ & 168 \\
\hline Ladurns & $88 \%$ & $100 \%$ & $94 \%$ & 172 \\
\hline Melag & $97 \%$ & $93 \%$ & $97 \%$ & 212 \\
\hline Obereggen & $90 \%$ & $94 \%$ & $97 \%$ & 230 \\
\hline Pfelders & $96 \%$ & $98 \%$ & $98 \%$ & 178 \\
\hline Piz la lla & $74 \%$ & $98 \%$ & $96 \%$ & 106 \\
\hline Prettau & $79 \%$ & $80 \%$ & $97 \%$ & 98 \\
\hline Rein in Taufers & $84 \%$ & $82 \%$ & $85 \%$ & 207 \\
\hline Stausee Neves & $83 \%$ & $83 \%$ & $83 \%$ & 201 \\
\hline Waidmannalm & $92 \%$ & $95 \%$ & $92 \%$ & 132 \\
\hline Weissbrunn & $93 \%$ & $97 \%$ & $96 \%$ & 287 \\
\hline \multicolumn{5}{|l|}{ TRENTINO } \\
\hline 10PM & $94 \%$ & $100 \%$ & $100 \%$ & 18 \\
\hline 11AN & $80 \%$ & $100 \%$ & $100 \%$ & 5 \\
\hline $12 \mathrm{FO}$ & $100 \%$ & $83 \%$ & $100 \%$ & 12 \\
\hline 14PO & $78 \%$ & $100 \%$ & $100 \%$ & 9 \\
\hline 16PT & $100 \%$ & $92 \%$ & $100 \%$ & 13 \\
\hline $18 S B$ & $100 \%$ & $33 \%$ & $100 \%$ & 12 \\
\hline $19 \mathrm{PF}$ & $67 \%$ & $93 \%$ & $100 \%$ & 15 \\
\hline 20BA & $67 \%$ & $100 \%$ & $100 \%$ & 6 \\
\hline $29 \mathrm{FL}$ & $73 \%$ & $100 \%$ & $100 \%$ & 30 \\
\hline 30PN & $100 \%$ & $83 \%$ & $100 \%$ & 42 \\
\hline 5PSV & $100 \%$ & $50 \%$ & $100 \%$ & 2 \\
\hline 8PAN & $50 \%$ & $100 \%$ & $100 \%$ & 2 \\
\hline \multicolumn{5}{|l|}{ TYROL } \\
\hline St.101303 & $67 \%$ & $66 \%$ & $67 \%$ & 312 \\
\hline St. 101501 & $79 \%$ & $77 \%$ & $80 \%$ & 352 \\
\hline St. 110296 & $88 \%$ & $90 \%$ & $92 \%$ & 329 \\
\hline St.113589 & $75 \%$ & $65 \%$ & $75 \%$ & 411 \\
\hline \multirow{3}{*}{ St. 114934} & $93 \%$ & $92 \%$ & $93 \%$ & 322 \\
\hline & Average agreement & Average agreement & Average agreement & Total points \\
\hline & $90 \%$ & $92 \%$ & $96 \%$ & 4625 \\
\hline
\end{tabular}

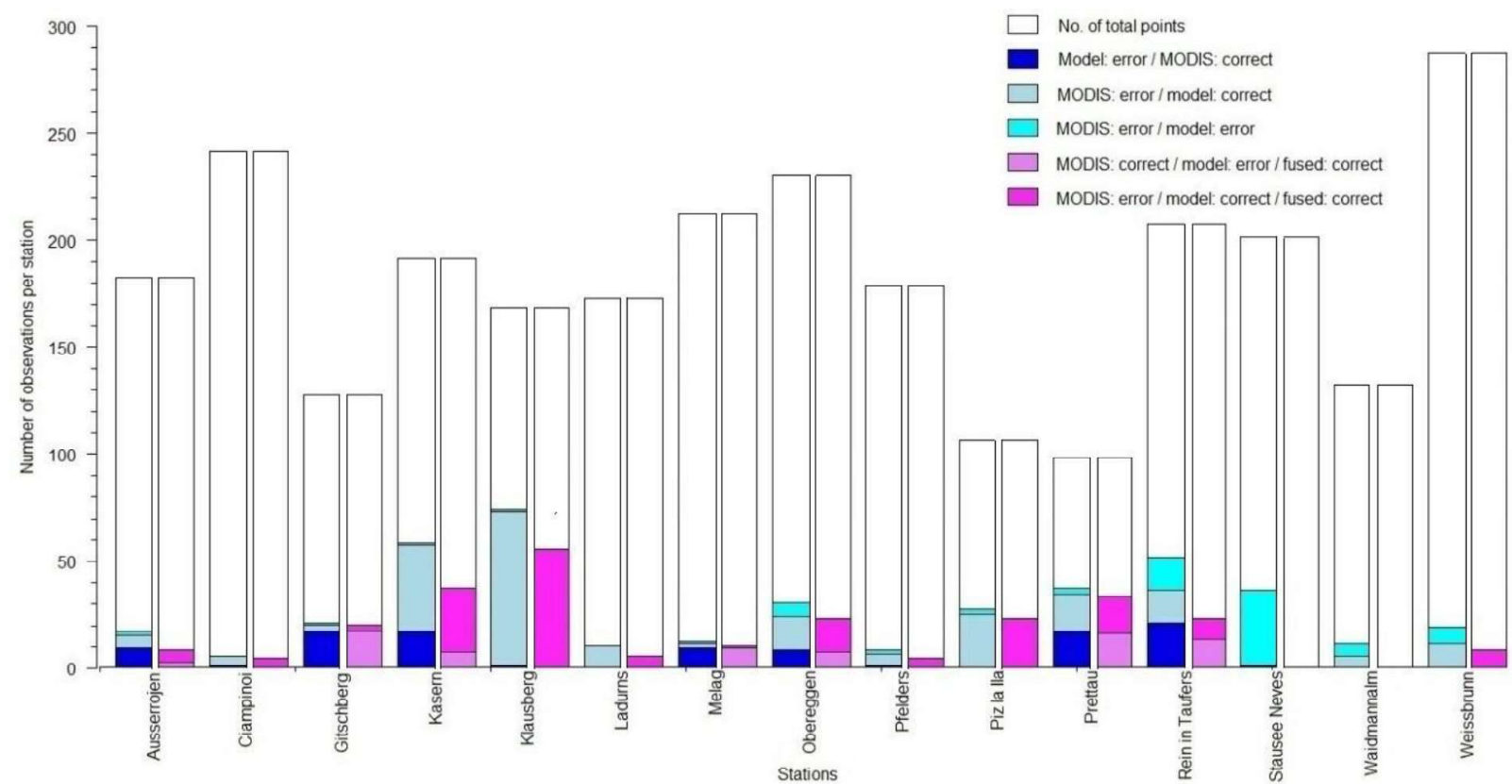

Fig. 6. Validation with ground data from measurement sites in South Tyrol: white bars indicate the total points for each station; dark blue marks points where MODIS is correct and AMUNDSEN is wrong with respect to ground data; light blue shows points where MODIS is wrong and AMUNDSEN is correct; cyan bars represent points where both MODIS and AMUNDSEN are wrong; light pink are points where the fused product is correct and equal to MODIS; dark pink are points where the fused product is correct and equal to AMUNDSEN. 
This behavior could be explained by considering that about $68 \%$ of considered disagreement points in South Tyrol correspond to measurement sites located in pixels classified as forest. This means that these sites are probably located near the forest and are representative of such type of land cover. The well-known problem of MODIS in detecting snow in these areas could lead the fusion method to be more confident with AMUNDSEN product. Moreover, approximately 38\% of the remaining disagreement points in open areas correspond to north-facing sites. In this case the lower reliability of MODIS product could be ascribed to the underestimation in low-light conditions which frequently happen during wintertime as reported in [32].

The same procedure has been applied to data collected in Trentino and in Tyrol.

For the data from the Trentino region, in 16 out of 28 measurement sites MODIS and AMUNDSEN are always in agreement and both accurately reproduce the ground observations. These sites are not shown in the histogram. As shown in Fig. 7, the points where MODIS and AMUNDSEN provide different results are correctly classified by the fusion procedure. Moreover, the points where MODIS and AMUNDSEN provide the same results are all correctly classified with respect to the observations. Hence, for the Trentino area and the period considered, the fused product is able to correct all errors present in the two snow cover maps. In particular, this total agreement of fused product with ground data is symmetrically distributed between the two sources of information: in $50 \%$ of cases the fused product matches the MODIS product and in the remaining 50\% it coincides with AMUNDSEN.

For the Tyrol region, $70 \%$ of the disagreement points have been correctly classified by the SVM classifier (Fig. 8). In about $74 \%$ of these correctly classified points, the fused product matches the MODIS product, whereas in the remaining $26 \%$ of cases it agrees with the modelled value. In this case, the behavior of fused product seems to be opposite to the one found in South Tyrol: fusion method seems to be more confident with MODIS product than with AMUNDSEN one. This could be ascribed to a lower number of disagreement points in forested areas. Unlike what happens in South Tyrol, in fact, in Tyrol most of the selected disagreement points (about 58\%) is associated to measurements sites located in pixels classified as open areas.

In order to understand if the differences with ground data are due to an underestimation or an overestimation of snow, the histogram in Fig. 9 shows, by considering all stations, the number of times where each snow cover map disagrees with the ground data, per month. From the histogram, the MODIS product underestimates the presence of snow in most cases, especially in December and January (value of the yellow bars). This behavior is in line with accuracy variation reported for standard MODIS product by NASA [43] and [44].

In the fused product, the smallest errors occur in February when the amount of snow is large. AMUNDSEN seems to produce the largest errors in spring, due to the accumulative nature of the errors in the computation of the accumulation, redistribution and melt processes [16]. This effect might lead to a higher uncertainty in snow detection in this period.

The decision fusion classifier has been applied to about 1300 maps in the considered simulation period to generate the resulting time series of fused snow maps.

The accuracy of snow detection from satellite data is, in general, significantly higher in open areas than in forested areas. Indeed, trees increase the complexity of the scene by masking the snow on the ground and altering the radiance measured by the MODIS satellite [45], [46].

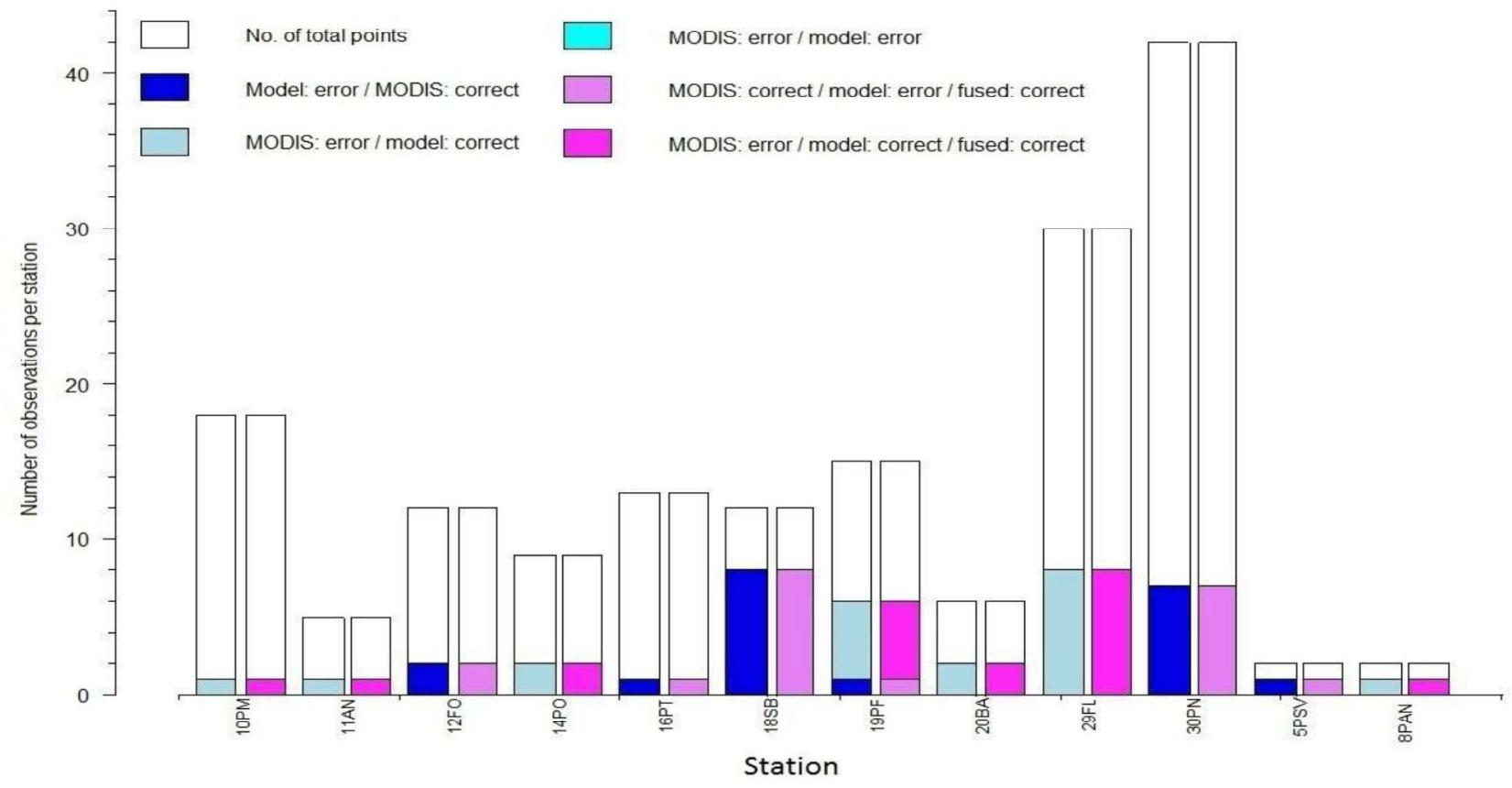

Fig. 7. Validation with ground data from measurement sites in Trentino. 
Since elevation also strongly affects quantity and distribution patterns of precipitation and snow, we analyzed the snow cover area (SCA) for different land use (i.e. forest and open areas) and elevation bands. Fig. 10 shows the SCA (i.e. the total number of snowcovered pixels divided by the total number of snow-covered and snow-free pixels) behavior in time of the three snow products for the entire period (October 2012 - July 2016).

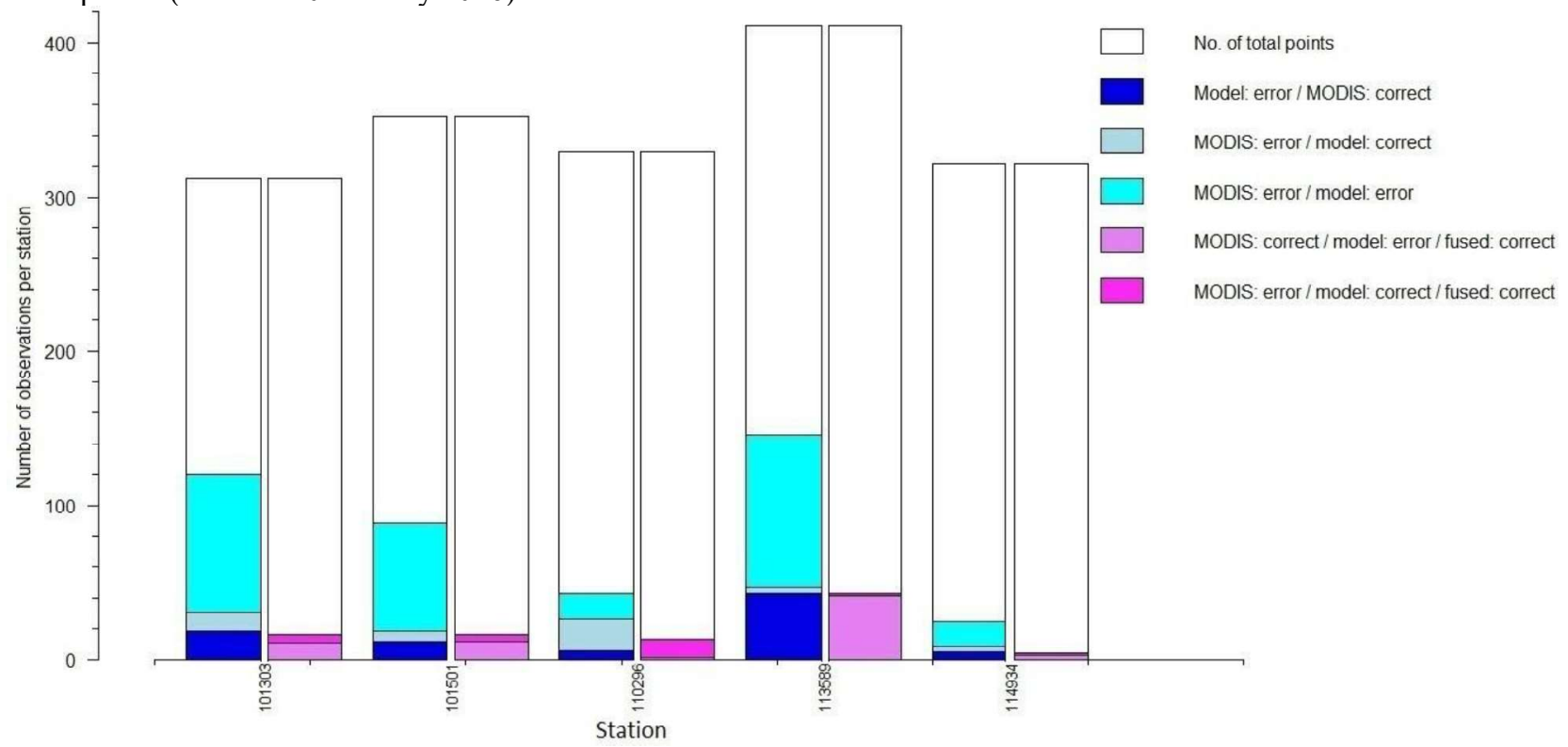

Fig. 8. Validation with ground data from measurement sites in Tyrol.

The underestimation of snow in forest as found in the MODIS product seems to be solved in the fused product, which follows the accurate simulation of the forest snow cover in AMUNDSEN: in forest, for all elevation bands, the fused product accurately reproduces the SCA peaks of winter season, also when there is a sharp underestimation in the MODIS product. In open areas, the behavior of AMUNDSEN and MODIS products is similar and the fused snow cover maps well reproduce the seasonal variability of the winter peaks and summer minima.

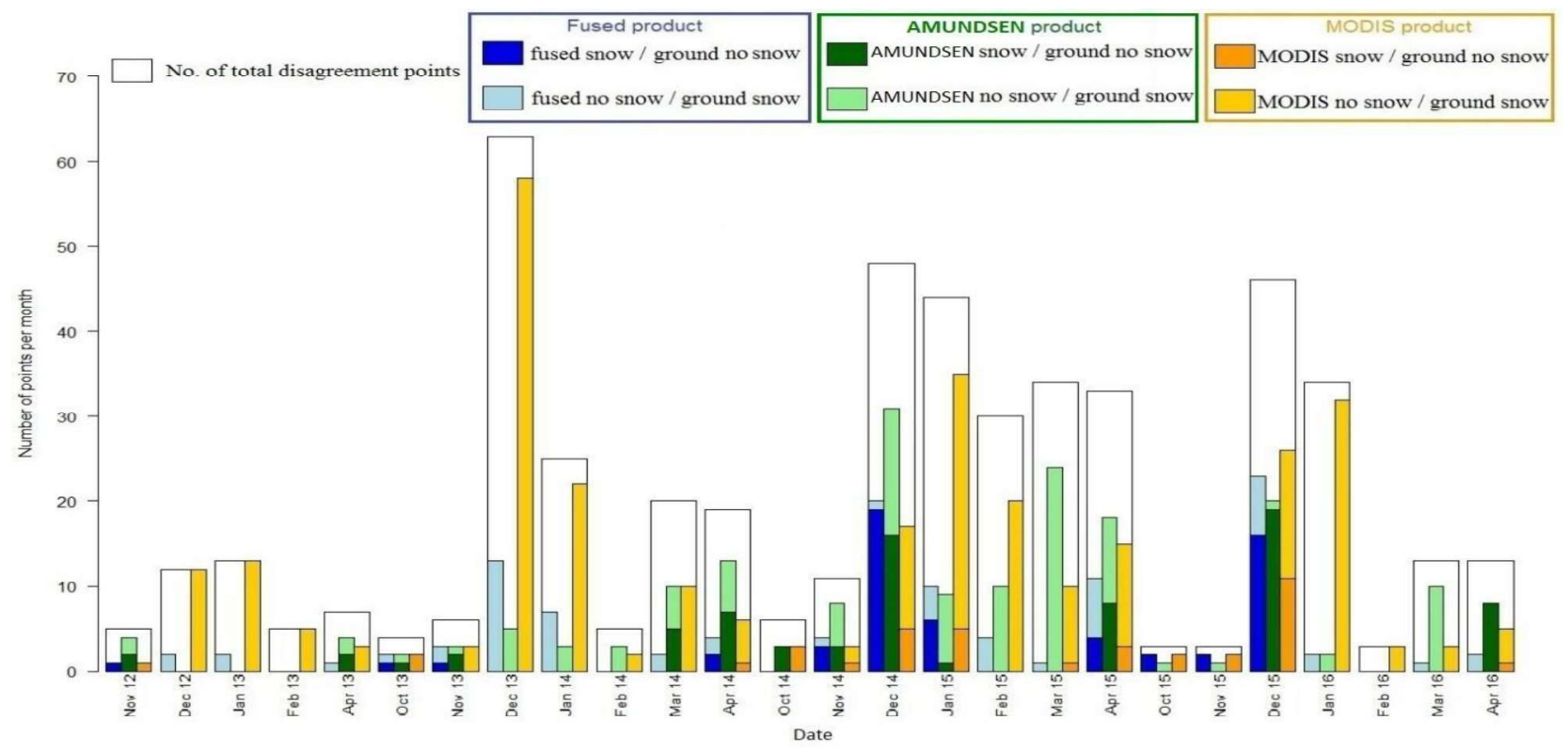

Fig. 9. Monthly difference between snow products and observations

\section{Cloud Effect Correction}

A further improvement of the final data fusion snow maps can be achieved by a cloud correction approach applied to the regions where the MODIS snow maps are incomplete, due to the cloud presence. Hence, the final product consists of a map having the pixel value obtained by the fusion method in those pixels where two original snow cover maps (MODIS and AMUNDSEN) disagree and the AMUNDSEN pixel value where MODIS indicates "cloud". 

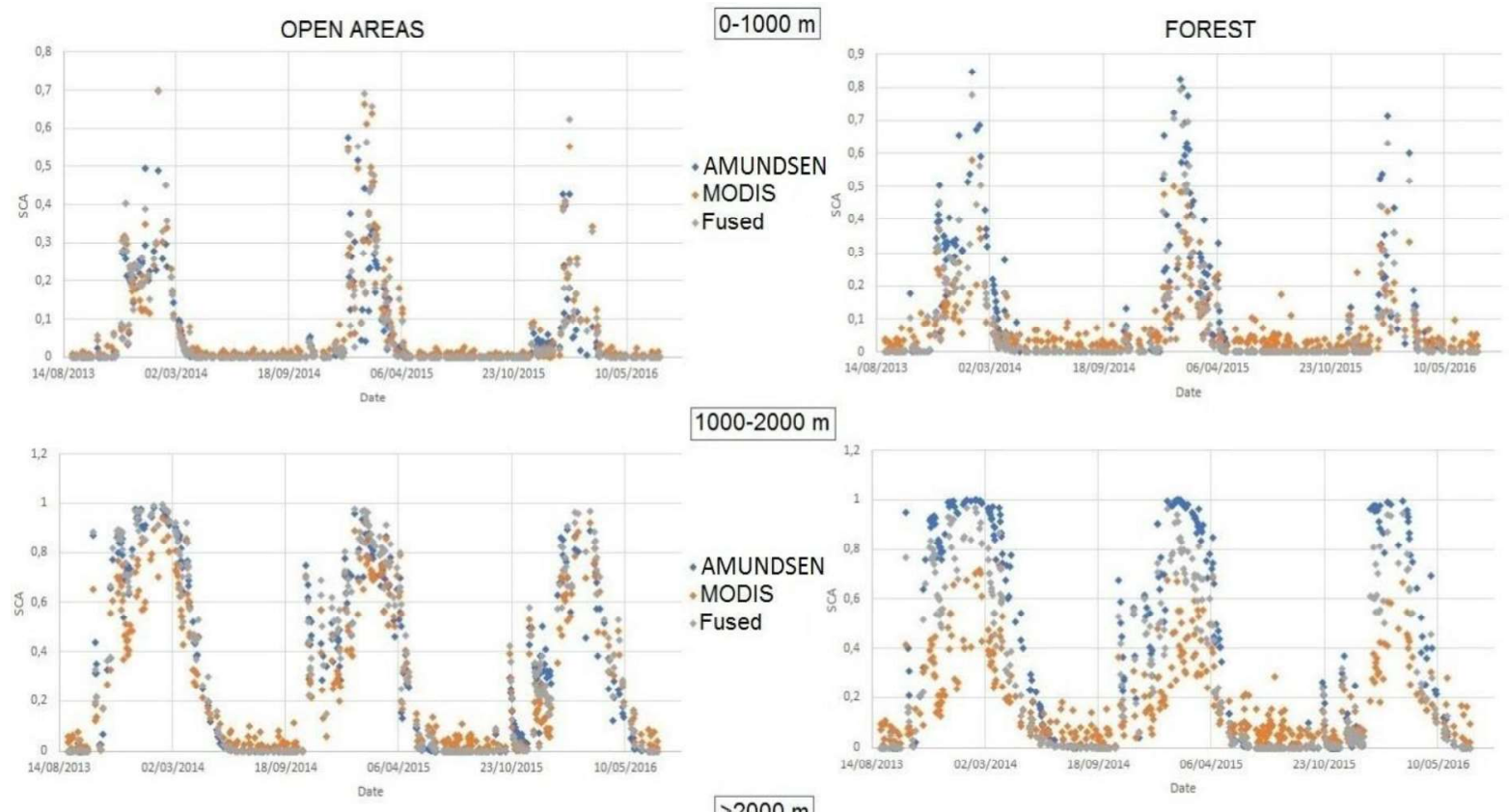

wationem
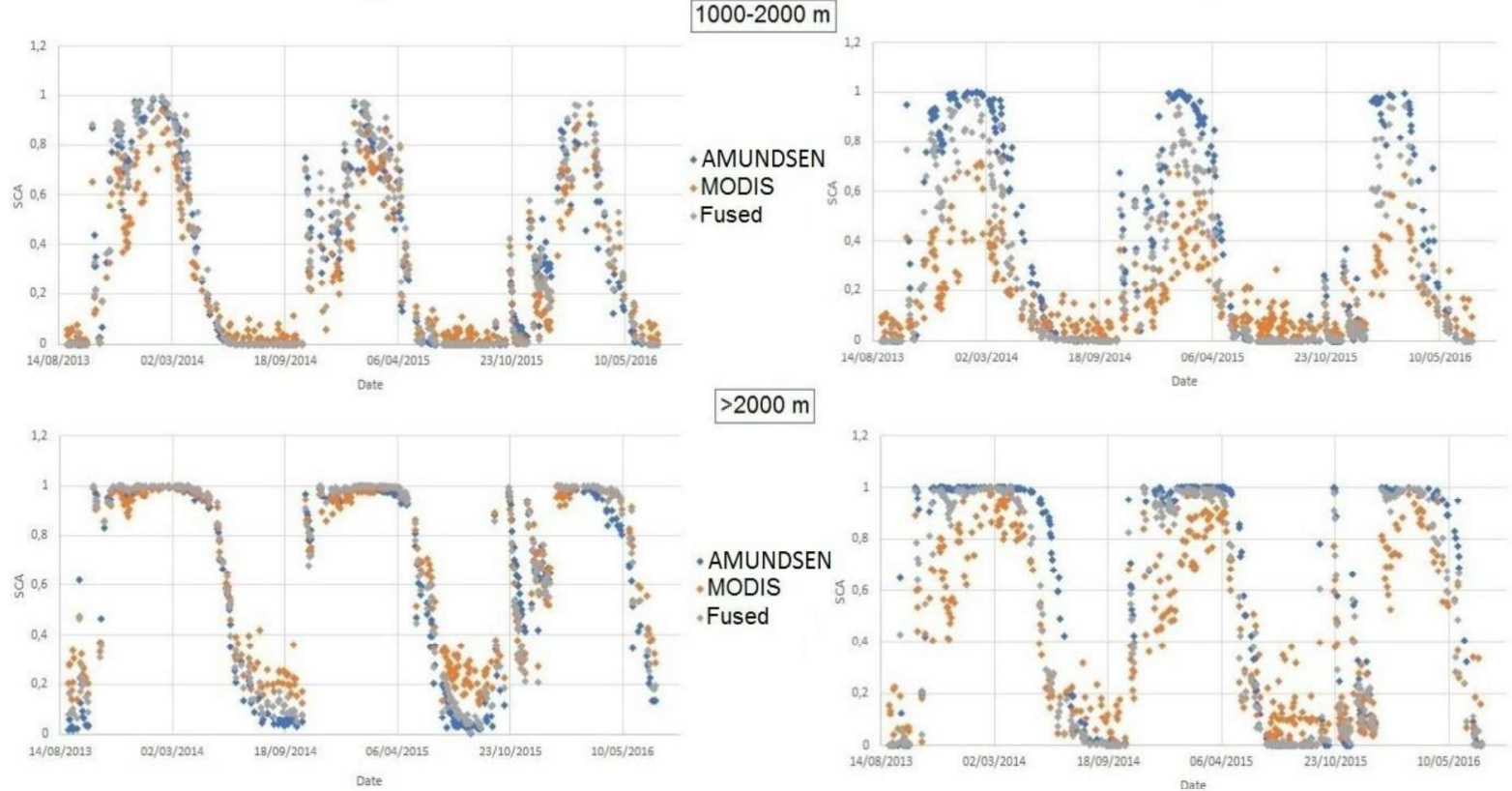

Fig. 10. Snow cover area (SCA) behavior in time for AMUNDSEN (blue), MODIS (orange) and the fused (grey) products, respectively. The analysis is carried out in open (left) and forested (right) areas for different elevation bands. The red circles in forested areas highlight the winter snow SCA peaks where the MODIS underestimation is more evident.

Fig. 11 shows two examples of snow maps at the end (on April 17th, 2014) of the winter season 2013-2014 and at the start (on November 23th, 2014) of winter season 2014-2015. The right figures show the images with clouds, whereas the left ones show the corrected images, as above explained. The colors highlight the different behaviors of the fused product: green and white represent the pixels where AMUNDSEN and MODIS agree and, therefore, where the data fusion approach is not applied and consequently has the same value of the two single sources; the dark and light blue are the pixels where the fused snow map has the same value of the MODIS map; finally, the dark and light pink indicate the pixel where the fused snow map follows the behavior of the AMUNDSEN simulation. In the winter image, most of the pixels classified as snow by AMUNDSEN as well as by the fused product (dark pink) are located on the northern exposure. This behavior may be ascribed to the MODIS underestimation in lowlight conditions which frequently happen during winter time as reported in [32]. The cyan color indicates that the fused product follows the MODIS product behavior in detecting the snow absence. Most of these areas are located in forest: as highlighted in Fig. 9, in forested area the fused product results follow the AMUNDSEN behavior because of the well-known limitation of optical satellites to detect snow under the canopy. In this context, it is worthwhile mentioning that snow detection in forest is very complex and it depends on many factors such as the location of the forest (north/south), the density of the forest, the type of the forest (broadleaf or conifer). It is found that normally MODIS product tends to underestimate the snow cover in forested areas [47], [48]. At the same time, at the beginning and end of the season, it can be supposed that AMUNDSEN model may simulate low values of SWE in these transient periods, so that SVM classifier can give in some cases, as shown in fig.10, the priority to the MODIS product. This behavior highlights the importance in the selection of the feature to be used in the data fusion approach, both the inputs and the related quality measures. These measures shall provide both an evaluation of the quality of the inputs and try as well to cover the different spatial and temporal variability, which the snow has in mountain areas. As a future step, different quality measures will be evaluated in order to understand their impact on the final products and how they can tackle the heterogeneity of snow cover in complex terrain. 


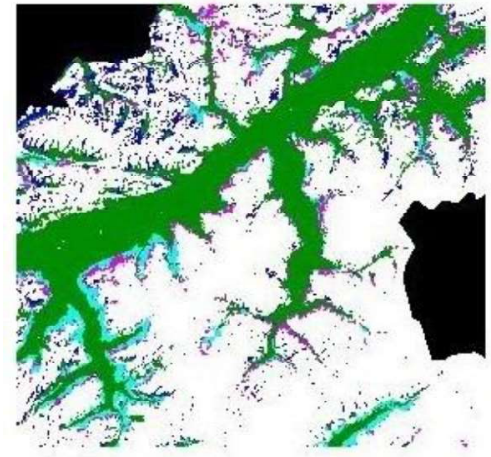

Cloud effect corrected

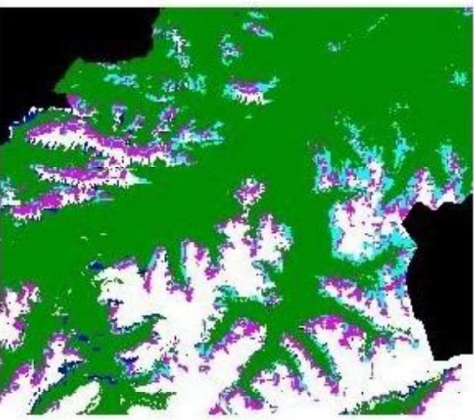

Date: 17-04-2014

$M=$ MODIS snow map $A=$ AMUNDSEN snow map $\mathrm{f}=$ fused snow map

no data/cloud

$M=A=f=$ no snow

$M=A=f=$ snow

$\mathrm{f}=\mathrm{M}=$ snow

$f=A=$ snow

$f=A=$ no snow

$\mathrm{f}=\mathrm{M}=$ no snow

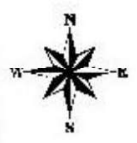

$\begin{array}{lllllll}0 & 4 & 8 & 12 & 16 & 20\end{array}$ सH户 05101520253035 सHझ $\rightleftharpoons \mathrm{Km}$

Map Scalc 1:850,000

Date: 23-11-2014

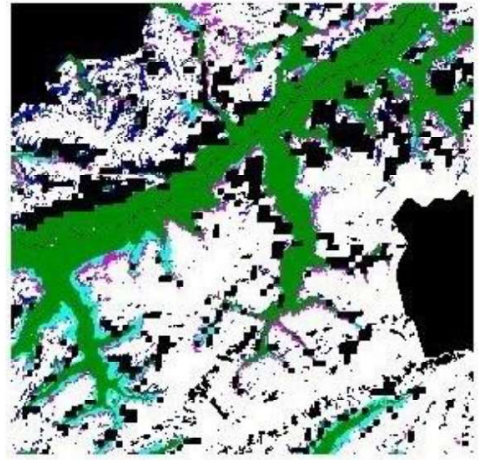

With clouds

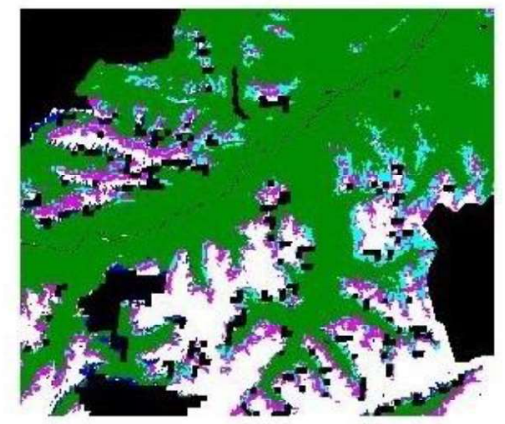

Fig. 11. Example of fused product, with clouds (right) and with cloud effect correction (left). The colors show the different behavior of the fused product.

\section{CONCLUSION AND OUTLOOK}

In this paper we present a method to overcome the limitations of existing remote sensing and modelling techniques for snow cover mapping. The data fusion approach developed takes advantage of the specific properties of the remote sensing data (such as independency from meteorological observations and a spatialized representation of snow cover) and those of a physical snow model (such as solid physical basis and the independency from cloud coverage). The objective of the data fusion is solving the ambiguity of disagreement points, i.e. those pixels where the snow model indicates snow presence and the satellite product snow absence (or vice versa).

The agreement points (where both MODIS and AMUNDSEN say "snow" or "no snow") cannot be improved from this fusion approach, but an analysis on these situations has been carried out in order to understand the behavior of products with respect to the ground data. In South Tyrol and Trentino less than 1\% of agreement pixels is wrongly classified and they occur especially in situation of shallow snowpack (less than $5 \mathrm{~cm}$, which is the threshold imposed on the ground snow height values to obtain binary values) when MODIS and AMUNDSEN say snow and the ground measurement registers no snow.

The case of Tyrol is slightly different because the ground data come from automatic nivometeorological stations. The snow height measurements are continuous and are also collected in the summer period. However, measurements in summer period are critical: the grass grows at stations and is measured by the ultrasonic sensor by causing a supposed increase in the height of the snowpack. If it snows in summer, the grass is flattened. A snowfall causes, thus, a sudden drop in the measured height.

Most of wrong classification of agreement pixels in Tyrol area occur in summer period, when measurements from automatic stations in summer are not reliable. Some cases occur at the beginning of the winter season with first snowfalls and shallow snowpack.

The fusion is carried out by means of an SVM, a pattern recognition technique often adopted in the field of bio-physical parameter retrieval for its capability to handle complex and non-linear problems and to manage different kinds of inputs.

The results show that the presented data fusion method is able to produce a more accurate snow cover map than could be provided by remote sensing or snow modelling alone. The validation of the fused snow cover product was performed by using ground data derived from measurements carried out in open sites in the test region, resulting in a very good agreement. The average accuracy of $90 \%$ (MODIS) and $92 \%$ (AMUNDSEN) is increased to $96 \%$ in the fused product. In future work we will extend the validation to forested sites.

Moreover, it is worth saying that the analysis of the uncertainties shows that there are very few cases in which they are similar (difference between AMUNDSEN and MODIS uncertainties lower than 10\%). These cases represent approximately the 3\% and 
usually occur in December and in April. SVR behavior in these cases strongly depend on period of the year: in spring season, in average, SVR seems to be more confident with MODIS product even in the cases when AMUNDSEN uncertainty is slightly lower than in MODIS. Vice versa, when the case of similar uncertainties occurs in December, the SVR follows the AMUNDSEN behavior.

This confirms that SVR approach is more than a simple classification based on uncertainties (choice of lower uncertainty) and that probably the regressor catches a seasonal trend from the training dataset that leads it to choose the most reliable product also depending on the period and not only on uncertainty values.

A further improvement was carried out by applying a cloud clearing that makes use of the snow model result in areas that are classified as "cloud" in the MODIS product. This procedure allows to obtain a final snow cover map with coverage on the entire area.

As further development, in addition to the two snow cover maps of satellite and model origin and their quality measures, other input features can be tested for the fusion procedure, e.g. the sun incident angle (to account for different illumination conditions) or the percentage of forest coverage in the pixel (to account the quality of remote sensing product that is, as mentioned, affected by this parameter).

These results are promising if compared to what already exists in the literature: Parajka and Blöschl [49] presented a method for improving the existing MODIS daily snow products by reducing cloud coverage. They improve the combined Aqua and Terra snow cover product by using first a spatial filter and then a temporal filter for reducing the cloud covered pixels. Their approach allows a reduction in cloud coverage of more than $95 \%$, with an overall annual accuracy of more than $92 \%$, based on a comparison with ground snow height measurements.

The same overall accuracy evaluation was applied by Pu et al. [50] who tested the MODIS 8-day composite snow product against ground snow height data on the Tibet Plateau. They reported an average of 90\% overall accuracy in the period $2000-2003$.

Şorman et al. [51] compared daily snow cover maps obtained from MODIS images with ground observations in mountainous terrain of Turkey for the winter season of 2002-2003 and 2003-2004 during the accumulation and ablation periods of snow.

The comparison shows good agreement with overall accuracies in between 62 to $82 \%$ considering a 2-day shift during cloudy days.

Results obtained in this work encourage further research on the development of a general method being able to provide improved snow cover maps, transferable even in other regions or to exploit this fusion method for retrieving other snow parameters, such as snow water equivalent (SWE).

Satellite products at high-medium resolution cannot deliver such variable and can contribute only with some auxiliary data. The objective of the fusion, in this case, will be the improvement of the reliability of physical model product by exploiting remotely sensed products as proxy information.

\section{ACKNOWLEDGMENTS}

The research was supported by the project CRYOMON- SciPro: Improve the Science of Processes within the Cryosphere by Integrating Hydrological Modelling with Remote Sensing in a Multi-Level Data Fusion Approach - a Contribution to Cryosphere Monitoring in the Euregio Region. The project was funded by the Euregio Science Fund 1st call, project number IPN 10.

For ground data we gratefully acknowledge:

The Hydrographic Service of Tyrol

The Autonomous Province of Bolzano, Agency for Civil Protection - Hydrographic Office (South Tyrol/ Alto Adige/ Südtirol)

The Autonomous Province of Trento - Risk prevention service, Forecasting and planning office; Giacomo Bertoldi and Christian Brida from Alpine Environment Institute, Eurac Research, viale Druso, 1-39100 Bolzano, Italy, for providing the contact with the Autonomous Province of Trento and the data.

\section{REFERENCES}

[1] P. Singh, and Singh, V.P., "Snow and Glacier Hydrology", Water Science and Technology Library, 37. Kluwer Academic Publishers, Dortrecht, Boston, 2001, 742 p.

[2] D.K. Hall, and G.A. Riggs, "Accuracy assessment of the MODIS snow products", Hydrological Processes: An International Journal, 21(12), pp. 1534-1547, 2007.

[3] D. Vikhamar, and R. Solberg, "Subpixel mapping of snow cover in forests by optical remote sensing". Remote Sensing of Environment, 84(1), pp. 69-82, 2003.

[4] P.T. Giles, "Remote sensing and cast shadows in mountainous terrain". Photogrammetric engineering and remote sensing, 67(7), pp. 833-840, 2001.

[5] H. Xie, X. Wang, and T. Liang, "Development and assessment of combined Terra and Aqua MODIS snow cover products in Colorado Plateau, USA and Northern Xinjiang, China", Journal of Applied Remote Sensing, 3, pp. 1-15, 2009.

[6] J. Parajka, and G. Blöschl, "Spatio-temporal combination of MODIS images -potential for snow cover mapping", Water Resources Research, 44, pp. 1-13, 2008.

[7] A. Gafurov, and A. Bardoyy, "Cloud removal methodology from MODIS snow cover product", Hydrology and Earth System Sciences, 13, pp. 1361-1373, 2009. 
[8] D. Vikhamar, and R. Solberg, "Subpixel mapping of snow cover in forests by optical remote sensing", Remote Sensing of Environment, 84(1), pp. 69-82, 2003.

[9] X.Y. Wang, J. Wang, Z.Y. Jiang, H.Y. Li, and X.H. Hao, "An Effective Method for Snow-Cover Mapping of Dense Coniferous Forests in the Upper Heihe River Basin Using Landsat Operational Land Imager Data", Remote Sensing, 7(12), pp. 17246-17257, 2015.

[10] A. Fahsi, T. Tsegaye, W. Tadesse, and T. Coleman, "Incorporation of digital elevation models with Landsat-TM data to improve land cover classification accuracy". Forest Ecology and Management, 128(1), pp. 57-64, 2000.

[11] A.R. Shahtahmassebi, K. Wang, Z. Shen, J. Deng, W. Zhu, N. Han, F. Lin, N. and Moore, "Evaluation on the two filling functions for the recovery of forest information in mountainous shadows on Landsat ETM+ Image", Journal of Mountain Science, 8(3), pp. 414-426, 2011.

[12] D.L. Civco, "Topographic normalization of Landsat Thematic Mapper digital imagery", Photogrammetric Engineering and Remote Sensing, 55(9), pp. 1303-1309, 1989.

[13] P.M. Dare, "Shadow analysis in high-resolution satellite imagery of urban areas", Photogrammetric Engineering \& Remote Sensing, 71(2), pp. 169-177, 2005.

[14] L.K. Dorren, B. Maier, and A.C. Seijmonsbergen, "Improved Landsat-based forest mapping in steep mountainous terrain using object-based classification", Forest Ecology and Management, 183(1), pp. 31-46, 2003.

[15] R. Essery, S. Morin, Y. Lejeune, and C. Bauduin-Menard, "A comparison of 1701 snow models using observations from an alpine site", Advances in Water Resources, 55, pp. 131-148, doi:10.1016/j.advwatres.2012.07.013, 2013.

[16] M. Zappa, F. Pos, U. Strasser, P. Warmerdam, and J. Gurtz, J., "Seasonal water balance of an Alpine catchment as evaluated by different methods for spatially distributed snowmelt modelling", Nordic Hydrol., 34 (3), 179-202, 2003.

[17] L.J. Renzullo, D.J. Barrett, A.S. Marks, M.J. Hill, J.P. Guerschman, Q. Mu, and S.W. Running, "Multi-sensor model-data fusion for estimation of hydrologic and energy flux parameters", Remote Sensing of Environment, 112(4), pp. 1306-1319, 2008.

[18] C. Cammalleri, M.C. Anderson, F. Gao, C.R. Hain, and W.P. Kustas, "A data fusion approach for mapping daily evapotranspiration at field scale", Water Resources Research, 49(8), pp. 4672-4686, 2013.

[19] T.H. Painter, D.F. Berisford, J.W. Boardman, K.J. Bormann, J.S. Deems, F. Gehrke, A. Hedrick, M. Joyce, R. Laidlaw, D. Marks, C. Mattmann, B. McGurk, P. Ramirez, M. Richardson, S.M.K. Skiles, F.C. Seidel, and A. Winstral, "The Airborne Snow Observatory: Fusion of scanning lidar, imaging spectrometer, and physically-based modeling for mapping snow water equivalent and snow albedo", Remote Sensing of Environment, 184, pp. 139-152, 2016.

[20] A. Prokop, "Assessing the applicability of terrestrial laser scanning for spatial snow depth measurements", Cold Reg. Sci. Technol. 54, pp. 155-163. http://dx.doi.org/10.1016/j.coldregions.2008.07.002, 2008.

[21] J.S. Deems, P.J. Gadomski, D. Vellone, R. Evanczyk, A.L. LeWinter, K.W. Birkeland, and D.C. Finnegan, "Mapping starting zone snow depth with a ground-based lidar to assist avalanche control and forecasting", Cold Reg. Sci. Technol. 120, pp. 197-204, 2015.

[22] A.J. Simmons, and A. Hollingsworth, "Some aspects of the improvement in skill of numerical weather prediction", Quarterly Journal of the Royal Meteorological Society, 128, pp. 647-677, 2002.

[23] G.C. Heathman, P.J. Starks, L.R. Ahuja, and T.J. Jackson, "Assimilation of surface soil moisture to estimate profile soil water content", Journal of Hydrology, 279, pp. 1-17, 2003.

[24] D.S. MacKay, S. Samanta, R. Nemani, and L.E. Band, "Multi-objective parameter estimation for simulating canopy transpiration in forested watersheds", Journal of Hydrology, 277, pp. 230-247, 2003.

[25] P.J. Rayner, M. Scholze, W. Knorr, T. Kaminski, R. Giering, and H. Widmann, "Two decades of terrestrial carbon fluxes from a carbon cycle data assimilation system", Global Biogeochemical Cycles, 19, GB2026. doi:10.1029/2004GB002254, 2005.

[26] W.J. Sacks, D.S. Schimel, R.K. Monson, and B.H. Braswell, "Model data synthesis of diurnal and seasonal CO2 fluxes at Niwot Ridge, Colorado", Global Change Biology, 12, pp. 240-259, 2006.

[27] D. Finger, M. Vis, M. Huss, and J. Seibert, "The value of multiple data set calibration versus model complexity for improving the performance of hydrological models in mountain catchments", Water Resources Research, 51(4), 1939-1958, 2015.

[28] F. Melgani, and L. Bruzzone, "Classification of hyperspectral remote sensing images with support vector machines", IEEE Transactions on geoscience and remote sensing, 42(8), pp. 1778-1790, 2004.

[29] F.A. Isotta, C. Frei, V. Weilguni, M. Perčec Tadić, P. Lassègues, B. Rudolf, V. Pavan, C. Cacciamani, G. Antolini, S.M. Ratto, M. Munari, S. Micheletti, V. Bonati, C. Lussana, C. Ronchi, E. Panettieri, G. Marigo, and G. Vertačnik, "The climate of daily precipitation in the Alps: development and analysis of a high-resolution grid dataset from pan-Alpine rain-gauge data", International Journal of Climatology, 34(5), 1657-1675, 2013.

[30] G. Zolezzi, A. Bellin, M.C. Bruno, B. Maiolini, and A. Siviglia, “Assessing hydrological alterations at multiple temporal scales: Adige River, Italy”, Water Resources Research, 45(June), pp. 1-15. doi:10.1029/2008WR007266, 2009.

[31] C. Notarnicola, M. Duguay, N. Moelg, T. Schellenberger, A. Tetzlaff, R. Monsorno, A. Costa, C. Steurer, and M. Zebisch, "Snow cover maps from MODIS images at $250 \mathrm{~m}$ resolution, Part 1: Algorithm description", Remote Sensing, 5(1), pp. 110-126, 2013.

[32] C. Notarnicola, M. Duguay, N. Moelg, T. Schellenberger, A. Tetzlaff, R. Monsorno, A. Costa, C. Steurer, and M. Zebisch, "Snow cover maps from MODIS images at 250 m resolution, Part 2: Validation. Remote Sensing, 5(4), pp. 1568-1587, 2013. 
[33] U. Strasser, "Die Modellierung der Gebirgsschneedecke im Nationalpark Berchtesgaden. Modelling of the mountain snow cover in the Berchtesgaden National Park", Berchtesgaden National Park research report, Nr. 55, Berchtesgaden. ISSN 01720023. ISBN 978-3-922325-62-8, 2011.

[34] U. Strasser, J. Corripio, B. Brock, F. Pellicciotti, P. Burlando, and M. Funk, "Spatial and Temporal Variability of Meteorological Variables at Haut Glacier d'Arolla (Switzerland) During the Ablation Season 2001: Measurements and Simulations", J. Geophys. Res., Vol. 109, D03103, doi:10.1029/2003JD003973, 2004.

[35] J. Corripio, "Vectorial algebra algorithms for calculating terrain parameters from DEMs and solar radiation modelling in mountainous terrain", International Journal of Geographical Information Science, 17(1), pp. 1-23, 2003.

[36] R. Essery, "A factorial snowpack model (FSM 1.0)", Geoscientific Model Development, 8(12), pp. 3867-3876, 2015.

[37] U. Strasser, M. Bernhardt, M. Weber, G.E. Liston, and W. Mauser, "Is snow sublimation important in the alpine water balance?", The Cryosphere, 2, 53-66, 2008.

[38] G.E. Liston, and K. Elder, “A Distributed Snow-Evolution Modeling System (SnowModel)”, J. Hydromet., 7(2), pp. 217$234,2006$.

[39] F. Hanzer, K. Helfricht, T. Marke, and U. Strasser, "Multi-level spatiotemporal validation of snow/ice mass balance and runoff modeling in glacierized catchments", The Cryosphere, 10, 1859-1881, http://dx.doi.org/10.5194/tc-10-1859-2016, 2016.

[40] G. Thirel, C. Notarnicola, M. Kalas, T. Schellenberger, A. Tetzlaff, M. Duguay, N. Mölg, P. Burek, A. de Roo, "Assessing the quality of a real-time Snow Cover Area product for hydrological applications", Remote Sensing of Environment 127, pp. 271287, 2012.

[41] E.P. Maurer, J.D. Rhoads, R.O. Dubayah, and D.P. Lettenmaier, "Evaluation of the snow-covered area data product from MODIS", Hydrological Processes, 17(1), 5pp. 9-71, 2003.

[42] A.E. Tekeli, Z. Akyürek, A.A. Şorman, A. Şensoy, and A.U. Şorman, "Using MODIS snow cover maps in modeling snowmelt runoff process in the eastern part of Turkey", Remote Sensing of Environment, 97(2), pp. 216-230, 2005.

[43] A. Simic, R. Fernandes, R. Brown, P. Romanov, and W. Park, "Validation of VEGETATION, MODIS, and GOES+ SSM/I snow-cover products over Canada based on surface snow depth observations", Hydrological Processes, 18(6), pp. 1089-1104, 2004.

[44] J. Parajka, and G. Blöschl, "Validation of MODIS snow cover images over Austria", Hydrology and Earth System Sciences Discussions, 3(4), pp. 1569-1601, 2006.

[45] D. Vikhamar, and R. Solberg, "Subpixel mapping of snow cover in forests by optical remote sensing", Remote Sensing of Environment, 84(1), pp. 69-82, 2003.

[46] X.Y. Wang, J. Wang, Z.Y. Jiang, H.Y. Li, and X.H. Hao, “An effective method for snow-cover mapping of dense coniferous forests in the upper Heihe river basin using Landsat operational land imager data", Remote Sensing, 7(12), pp. 17246-17257, 2015.

[47] D. Vikhamar, and R. Solberg, "Snow-cover mapping in forests by constrained linear spectral unmixing of MODIS data", Remote Sensing of Environment, 88(3), 309-323, 2003.

[48] R. Solberg, D. Hiltbrunner, J. Koskinen, T. Guneriussen, K. Rautiainen, and M. Hallikainen, "Snow algorithms and products - Review and recommendations for research and development", NR Report No. 924, Norwegian Computing Center, Oslo, Norway, 1997.

[49] Parajka, J. and Blöschl, G. (2008). Spatio-temporal combination of MODIS images-potential for snow cover mapping. Water resources research, 44(3).

[50] Pu, Z., Xu, L. and Salomonson, V. V. (2007). MODIS/Terra observed seasonal variations of snow cover over the Tibetan Plateau. Geophysical Research Letters, 34(6).

[51] Şorman, A. Ü., Akyürek, Z., Şensoy, A., Şorman, A. A. and Tekeli, A. E. (2007). Commentary on comparison of MODIS snow cover and albedo products with ground observations over the mountainous terrain of Turkey. Hydrology and Earth System Sciences, 11(4), 1353-1360. 